\title{
Lipoprotein(a) the Insurgent: A New Insight into the Structure, Function, Metabolism, Pathogenicity, and Medications Affecting Lipoprotein(a) Molecule
}

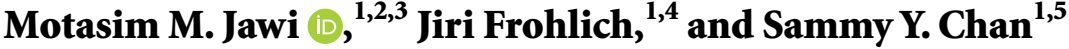 \\ ${ }^{1}$ Healthy Heart Program, St. Paul's Hospital, Vancouver V6Z 1Y6, Canada \\ ${ }^{2}$ Division of Experimental Medicine, Department of Medicine, Faculty of Medicine, University of British Columbia, \\ Vancouver V5Z 1M9, Canada \\ ${ }^{3}$ Department of Physiology, Faculty of Medicine, University of Jeddah, P.O. Box: 24, Jeddah 21959, Saudi Arabia \\ ${ }^{4}$ Department of Pathology and Laboratory Medicine, Faculty of Medicine, University of British Columbia, Vancouver, \\ British Columbia V6T 2B5, Canada \\ ${ }^{5}$ Department of Medicine, Division of Cardiology, University of British Columbia, Vancouver V5Z 1M9, Canada
}

Correspondence should be addressed to Motasim M. Jawi; motasim.jawi@gmail.com

Received 26 June 2019; Accepted 17 August 2019; Published 1 February 2020

Academic Editor: Xian-Cheng Jiang

Copyright (C) 2020 Motasim M. Jawi et al. This is an open access article distributed under the Creative Commons Attribution License, which permits unrestricted use, distribution, and reproduction in any medium, provided the original work is properly cited.

\begin{abstract}
Lipoprotein(a) [Lp(a)], aka "Lp little a", was discovered in the 1960s in the lab of the Norwegian physician Kåre Berg. Since then, we have greatly improved our knowledge of lipids and cardiovascular disease (CVD). Lp(a) is an enigmatic class of lipoprotein that is exclusively formed in the liver and comprises two main components, a single copy of apolipoprotein (apo) B-100 (apo-B100) tethered to a single copy of a protein denoted as apolipoprotein(a) apo(a). Plasma levels of Lp(a) increase soon after birth to a steady concentration within a few months of life. In adults, $\mathrm{Lp}$ (a) levels range widely from $<2$ to $2500 \mathrm{mg} / \mathrm{L}$. Evidence that elevated Lp(a) levels $>300 \mathrm{mg} / \mathrm{L}$ contribute to CVD is significant. The improvement of isoform-independent assays, together with the insight from epidemiologic studies, meta-analyses, genome-wide association studies, and Mendelian randomization studies, has established Lp(a) as the single most common independent genetically inherited causal risk factor for CVD. This breakthrough elevated Lp(a) from a biomarker of atherosclerotic risk to a target of therapy. With the emergence of promising second-generation antisense therapy, we hope that we can answer the question of whether $\mathrm{Lp}(\mathrm{a})$ is ready for prime-time clinic use. In this review, we present an update on the metabolism, pathophysiology, and current/future medical interventions for high levels of $\operatorname{Lp}(\mathrm{a})$.
\end{abstract}

\section{Introduction}

Atherosclerosis is a chronic inflammatory lipid-fueled disease of the arteries that is initiated very early in childhood and mediated by innate and adaptive immune responses. Atherosclerosis is characterized by progressive accumulation of lipids, necrotic cell debris, and extracellular matrix proteins in the vessel wall and eventually results in partial or total vessel occlusion or thrombosis due to rupture or erosion of the atherosclerotic plaque. Atherosclerosis reveals itself clinically later in life and is influenced by genetic, environmental, behavioral, and dietary risk factors [1-3]. The main risk factors for atherosclerosis include hypercholesterolemia, diabetes, cigarette smoking, and hypertension. Hypercholesterolemia, for instance, increases the permeability of the vessel walls and initiates the pathogenesis of the disease [4]. The Framingham study showed that low-density lipoprotein cholesterol (LDL$\mathrm{C}$ ), triglyceride (TG), and high-density lipoprotein cholesterol (HDL-C) are the major independent predictors of future atherosclerotic events [4]. The need to pinpoint further causal risk factors and thus prospective targets for future interventions is evident [5] by the fact that atherosclerosis is the still the principal cause of cardiovascular disease (CVD) death worldwide despite the decline in mortality rate due to advances 
in its diagnosis, treatment, prevention, and rehabilitation [6, 7]. Currently, lipoprotein(a) [Lp(a)], aka "Lp little a", is considered a likely candidate and independent strong predictor of atherosclerosis.

Lp(a) was first discovered by the Norwegian physician Kåre Berg almost six decades ago [8]. It is an enigmatic class of lipoprotein particles found in plasma and is assumed to be a genetic variant of LDL [9]. The Lp(a) protein moiety comprises two components, a single copy of apolipoprotein (apo) B-100 (apo-B100) tethered to a single copy of a protein denoted as apolipoprotein(a) $[\operatorname{apo}(a)]$. Apo(a) is a polymorphic glycoprotein and carbohydrate-rich moiety whose mRNA is expressed almost entirely in the liver [10]. Lp(a) also has a lipoprotein unit that is essentially identical to LDL both in make-up and in its physical and chemical characteristics [11]. Because Lp(a) and LDL are metabolically distinct due to the presence of apo(a), the special properties of $\mathrm{Lp}(\mathrm{a})$, including its mass and density heterogeneity, are virtually totally produced by apo(a) [11]. The discovery that apo(a) has homology with plasminogen (PLG), a substantial enzyme in fibrinolysis, suggested a theoretical association between $\mathrm{Lp}(\mathrm{a})$ and thrombosis [12]. The gene controlling the plasma $\mathrm{Lp}(\mathrm{a})$ concentration is the LPA gene, which evolved through replication and modification of the kringle $(\mathrm{K})$ domains of the PLG gene. In contrast to LDL-C, which follows a normal Gaussian distribution in the population, $\mathrm{Lp}(\mathrm{a})$ levels skew toward lower values in most populations studied to date [13], with most individuals with low $\mathrm{Lp}(\mathrm{a})$ levels and a tail of individuals who display high $\mathrm{Lp}(\mathrm{a})$ levels and corresponding prominent CVD risk [14]. Ethnicity powerfully impacts Lp(a) plasma concentrations: Caucasians tend to have the lowest Lp(a) levels, and African Americans have the highest [14]. However, it has become clear that the risk of developing coronary artery disease $(C A D)$ in Caucasians is more than two times higher in individuals with increased $\operatorname{Lp}(\mathrm{a})$ levels $[15,16]$. Several Mendelian randomization studies and meta-analyses have shown undoubted proof that elevated Lp(a) plasma concentrations are correlated with an amplified risk of myocardial infarction, stroke, and aortic valve stenosis [17]. Notwithstanding extensive investigations, the causal mechanisms behind how $\mathrm{Lp}$ (a) giving rise to atherosclerotic vascular diseases are still partly understood [18]. In this review, we present an update on the metabolism, pathophysiology and current/future medical interventions for high Lp(a) levels.

\section{Lp(a) Molecule}

2.1. Structure of $L p(a)$ Molecule. Lp(a) has multiple components (see Figure 1(a)) and mainly resembles and consists of an LDL-C molecule. Similar to LDL, Lp(a) has a hydrophilic apo-B100 component located around a lipid core of cholesteryl esters (CEs) and triacylglycerols with many phospholipids and unesterified cholesterol at its surface [19]. According to Siekmeier et al. [20], "corresponding to the physical resemblance to LDL, both lipoproteins are very indistinguishable to each other with respect to their structure" [21] (see Figure 1(b)). However, Lp(a) is distinguished from LDL-C by its hydrophilic highly glycosylated apo(a) portion (the PLG-like pathogenic component of $\mathrm{Lp}(\mathrm{a})$ ) [17]. In fact, the presence of apo(a) distinguishes $\operatorname{Lp}(\mathrm{a})$ from all other lipoprotein classes [22]. Apo(a) is covalently connected to apo-B100 via a single disulfide thioester bond through cysteine residues located in both proteins $[18,23]$, and these residues represent $88 \%$ of the total protein mass in Lp(a) [24]. Apo(a) is the key component of $\mathrm{Lp}(\mathrm{a})$ and evolved from the PLG gene superfamily a very long time ago through duplication and remodeling. Apo(a) existence imparts distinctive synthetic, catabolic, and functional characteristics along with a huge size heterogeneity $[17-19,23]$. In addition to apo(a) and apo-B100, a recent proteomic study has shown that $\mathrm{Lp}(\mathrm{a})$ has 33 more proteins associated with its surface that might be involved in lipid metabolism processes, inflammatory response, and coagulation processes [25].

2.2. Similarity to Plasminogen. The protease zymogen PLG acts like a proenzyme that is transformed to the fibrinolytic enzyme plasmin by a ternary multicomponent protein that is associated with tissue PLG activator (tPA), PLG, and fibrin either endogenously or iatrogenically [17]. A previous examination of an apo(a) cDNA from a human hepatocyte library revealed that apo(a) has outstanding physical similarities with PLG $[12,19]$. Apo(a) and PLG share high amino acid sequence similarity in several regions, including the protease domain and the Danish pastry-like structure referred to Kringles (K) type 4 (K4) and type $5(\mathrm{~K} 5)[19,23]$. Each kringle contains six conserved cysteine residues that form three disulfide bonds to provide the characteristic triple loop structure of the kringles [22]. These loop-like structures are also present in other coagulation factors, such as PLG, prothrombin, urokinase, and tissue-type PLG activators [8]. In contrast, PLG also has three more Kringles (K1 to K3) (see Figure 1(a)). Unlike PLG, apo(a) contains 10 subtypes of K4 (KIV ${ }_{1}$ to $\mathrm{KIV}_{10}$ ); $\mathrm{KIV}_{1}$ and $\mathrm{KIV}_{3}$ to $\mathrm{KIV}_{10}$ have a single copy, and $\mathrm{KIV}_{2}$ has repeated copies. Each KIV repeat contains three internal disulfide bonds, one $\mathrm{N}$-linked bond, and six potential O-linked glycosylation sites [26]. It is noteworthy that apo(a) has an inactive serine protease-like domain that cannot be activated by tPA and urokinase PLG activator (uPA) to become an active plasmin even though it has an intact Ser-His-Asp triad $[27,28]$. This characteristic may suggest that Lp(a) can hamper the physiologic properties of PLG in the fibrinolytic cascade [27]. This characteristic may suggest that Lp(a) can hamper the physiologic properties of PLG in the fibrinolytic cascade [27].

2.3. The Functions of Specific Kringles. The kringles on apo(a) serve critical functions (e.g., $\mathrm{KIV}_{10}$ is responsible for the important lysine-binding properties of $\operatorname{Lp}(\mathrm{a})$ ). Several other kringles play critical pathobiological roles, such as $\mathrm{KIV}_{(6-7)}$, which interact with scavenger receptors on foam cells [29]. This interaction results in the secretion of proinflammatory cytokines, such as interleukin (IL)-1, IL-6, and matrix metalloproteinases (MMPs), which can amplify the local inflammatory response and stimulate vascular smooth muscle cell (VSMC) proliferation and initial migration toward the atherosclerotic lesion $[13,29,30]$. Moreover, $\mathrm{KIV}_{(7-8)}$ are essential for $\operatorname{Lp}(\mathrm{a})$ formation due to the weak lysine binding 


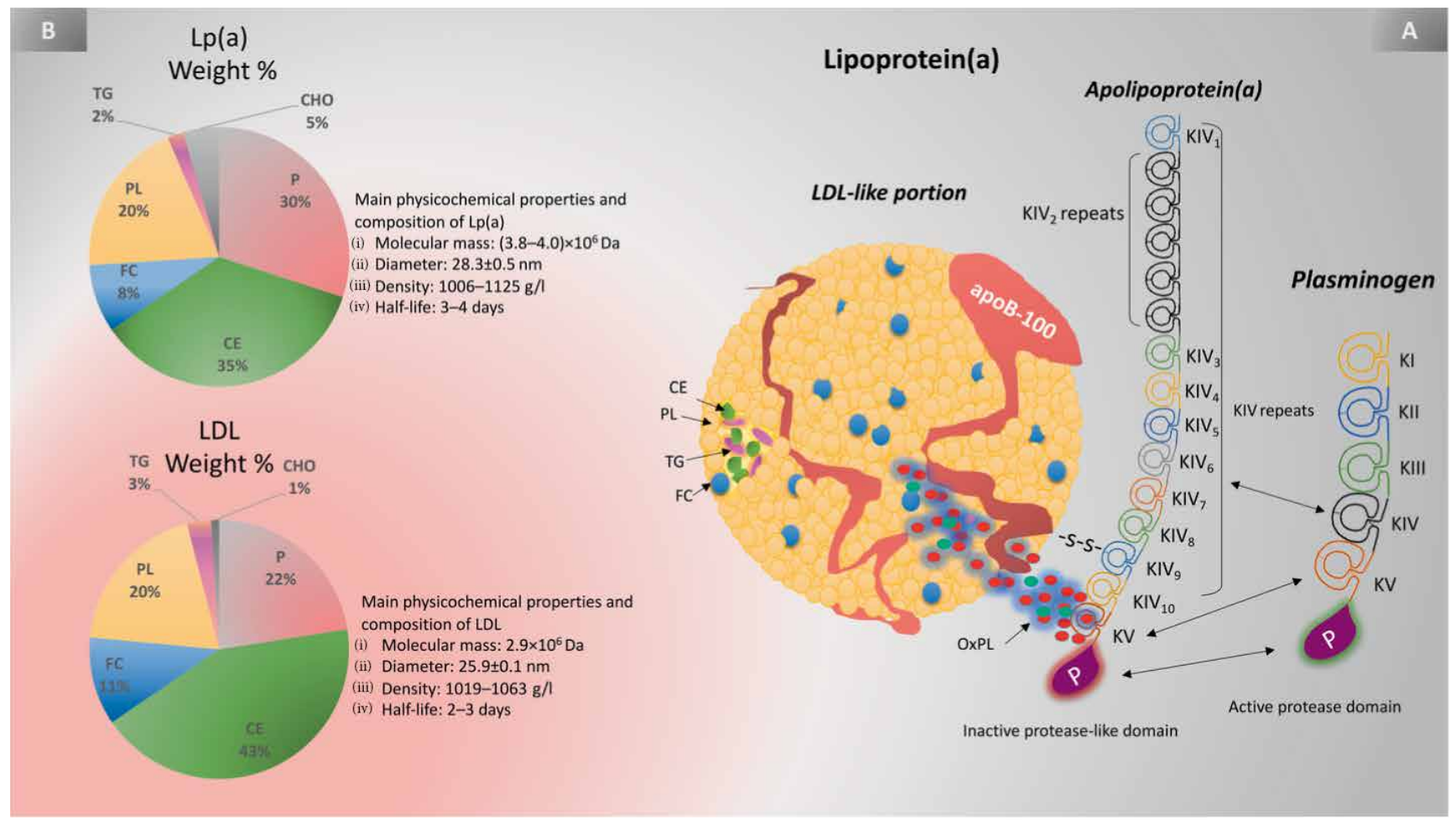

FIGURE 1: Lp(a) structure, composition, and physicochemical properties. A-Lp(a) is composed of apo-B100 covalently fastened together with apo(a), which originates from kringle IV (KIV) and KV, and the inactive protease domain of PLG. Apo(a) has important differences compared with PLG. (1) Apo(a) has an unpaired cysteine and forms a disulfide bond with apoB to generate the lipoprotein particle Lp(a). (2) Apo(a) has an inactive protease domain. (3) Apo(a) includes 10 subtypes of KIV repeats, composed of 1 copy each of KIV1, multiple copies of KIV2, and 1 copy of KIV310, KV, and an inactive protease-like domain. (4) Apo(a) lacks kringles 1-3 of PLG but has kringles 5 and 10 of $\mathrm{KIV}$, of which $\mathrm{KIV}_{2}$ is present in numerous repeats. OxPLs exist covalently bonded to the apo(a) component and are suspended in the lipid phase of apo-B100. B-Comparison between Lp(a) and LDL with regard to their composition and physicochemical properties.

sites (LBS) among these Kringles [29]. LBS are critical in the creation of the noncovalent apo(a)-LDL complex by allowing the free cysteine in $\mathrm{KIV}_{9}$ to form a covalent disulfide bridge to the apo-B100 component of LDL. The presence of strong LBS within these Kringles, particularly in $\mathrm{KIV}_{10}$, significantly enhances the capacity of $\operatorname{Lp}(a)$ to attach to and remain in vessel wall cells and fibrin and may thus be crucial to the atherothrombotic nature of $\mathrm{Lp}(\mathrm{a})$ [29].

\subsection{The Influence of the LPA Gene on Size and} Concentration. Inheritance of the $\mathrm{Lp}(\mathrm{a})$ molecule is dominant and was initially described as a dichotomous and qualitative (Lp+, Lp-) genetic trait [8]. However, it soon became apparent that the genetic variation is related to the levels of $\operatorname{Lp}(\mathrm{a})$ in the sera of different individuals (quantitative) rather than to the simple presence or absence of the $\mathrm{Lp}(\mathrm{a})$ molecule (qualitative) $[31,32]$. The gene that retains $90 \%$ of the control of apo(a) levels [33] is the LPA gene, which is located at positions 26 and 27 on the long arm of chromosome 6 (6q26-27) [23]. In fact, the LPA gene is one of the most potent monogenetic risk factors for CAD regardless of race [17]. No other quantitative trait is as influenced by sequence differences at a single locus as is $\operatorname{Lp}(\mathrm{a})$ [33]. This gene is accountable for the substantial size heterogeneity of apo(a) isoforms [34], which is associated with the variable number of copies (repeats) of kringle $\mathrm{KIV}_{2}$, ranging from 2 to more than 50 repeats with substantial size polymorphism (200-800 kilodaltons) [35] (see Figure 2).

The largest apo(a) isoform described so far has 52-54 KIV repeats [36]. This size variability is a unique phenomenon, as other lipoproteins usually have constant masses [17]. Up to $80 \%$ of individuals carry two different size alleles of apo(a), each inherited from one parent [34]. Thus, individuals may have two large, two small, or mixed-size apo(a) molecules. Generally, within individuals, the smaller isoform contributes more to net apo(a) production and concentration than does the larger isoform [17, 34]. Consequently, apo(a) isoform size is inversely related to $\mathrm{Lp}$ (a) density and plasma concentration $[19,37,38]$. This relationship might occur because small apo(a) size results in easy secretion by the liver, which leads to higher $\mathrm{Lp}(\mathrm{a})$ concentration and increases the cardiovascular risk and vice versa [39].

\section{Metabolism of Lipoprotein(a)}

3.1. Synthesis of Lipoprotein(a). Lp(a) synthesis occurs exclusively in the liver, and the LPA gene mainly influences Lp(a) production $[18,37,40]$. Many studies have confirmed that diet and environmental factors have minimal to no impact on $\mathrm{Lp}(\mathrm{a})$ [17]. According to Hobbs and White [33], the rate 


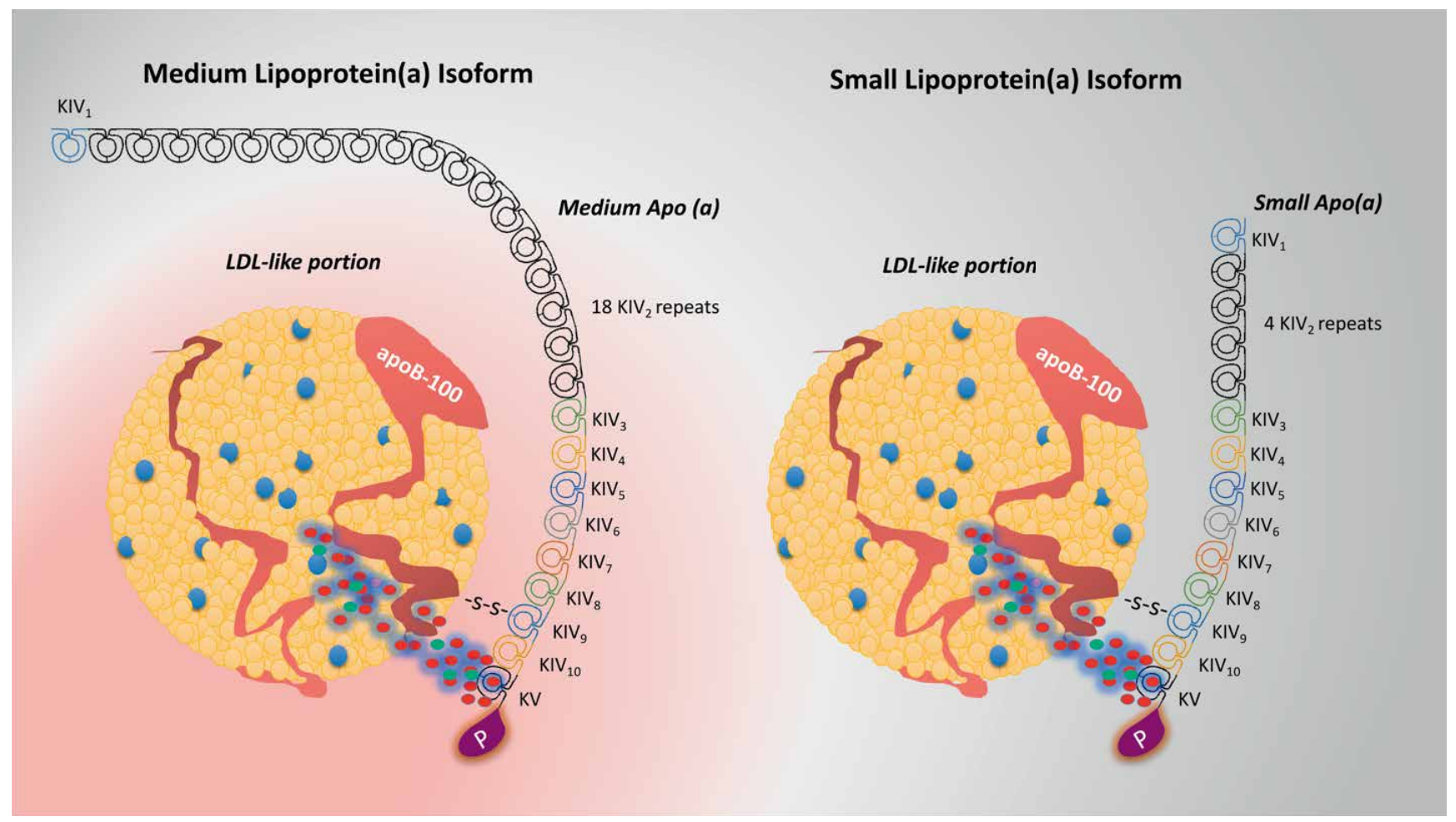

Figure 2: Comparison between different Lp(a) isoform sizes. In these 2 illustrations, apo(a) molecules of 4 (right) and 18 (left) KIV ${ }_{2}$ repeats are presented, representing 13 and 27 total KIV repeats.

of apo(a) secretion is determined by different stages inside the hepatocyte: first, the transcription of the apo(a) gene and apo(a) mRNA stability stage; second, apo(a) translation, which is believed to have a dominant influence on the production rate; third, extensive posttranslation modifications, including the formation of three disulfide bonds and the addition of an N-linked glycan, which is essential for folding [26], of apo(a) kringles in the endoplasmic reticulum (ER) [33] and subsequent transport out of the ER [33]; fourth, transport to the Golgi complex, where N-linked and O-linked glycans are further processed [33]; fifth, Golgi-specific addition and modification of apo(a) carbohydrates [41]; and sixth, transport to the cell surface [42]. Many in vivo studies suggest that the third step is the most important step in the production of apo(a) [10,43]. White and colleagues [43] have demonstrated using baboon liver cells that this inverted association could be accounted for by differences in the rate and the extent to which apo(a) isoform chains were processed through the ER. Specifically, these researchers verified that small apo(a) chains more completely and swiftly exit the ER than do large apo(a) chains [10].

3.2. Assembly of Lipoprotein(a). Assembly is a two-step procedure. First, to promote, mediate, and reinforce the association between the two apo components of $L p(a)$, the apo(a)-cysteines (Cys-4057) located at $\mathrm{KIV}_{3-7}$ are positioned close to the only free cysteine (Cys-3734) in apo-B100 via a noncovalent interaction [36, 44]. Second, a covalent disulfide bridge is established between $\mathrm{KIV}_{9}$ of apo(a) and apo-B100 of the LDL component [44]. The site of assembly is controversial.
The main theory is that assembly occurs either on the surface of the liver cells or in the space of Disse $[45,46]$. White and Lanford [43] used primary cultures of baboon liver cells to analyze the stages of $L p(a)$ biogenesis. Their study proved that the $\mathrm{Lp}(\mathrm{a})$ association was extracellular because it was inhibited when anti-apo(a) serum was present in the culture medium [43]. In contrast, according to Frank et al. [47], mixing recombinants of apo(a) with LDL-C in vitro and incubating the mixture for a few minutes leads to the formation of an intact $\mathrm{Lp}(\mathrm{a})$ particle that is entirely similar to the native $\mathrm{Lp}(\mathrm{a})$. The latter theory leads to the assumption that assembly may occur in either the plasma or the interstitial space $[44,47$, 48]. It is worth noting that although apo(a) is predominantly attached to LDL, 2-5\% apo(a) is free and present in the plasma [49].

The new secreted apo(a) is associated with a recently produced apoB-containing TG-abundant molecule to form Lp(a) with very-low-density lipoprotein (VLDL) properties (see Figure 3), which can correspondingly be transformed into a cholesterol-abundant unit with LDL properties $[43,46]$. Additionally, the linkage could directly occur with a molecule with LDL properties. In the bloodstream, the TG-abundant $\mathrm{Lp}(\mathrm{a})$ molecule is swiftly subjected to lipolysis by lipoprotein lipase to form a TG-remnant $\mathrm{Lp}(\mathrm{a})$ molecule that is directly catabolized, allowing apo(a) to be recycled [50] to the recently secreted apo(a) pool by the liver [46]. The recycled apo(a) then associates with an additional newly synthesized TG-abundant LDL molecule or is finally eliminated from the plasma by the liver or perhaps by the kidney [46]. TG synthesis may also be critical for the synthesis of apo(a) by hepatoma cells [51]. 


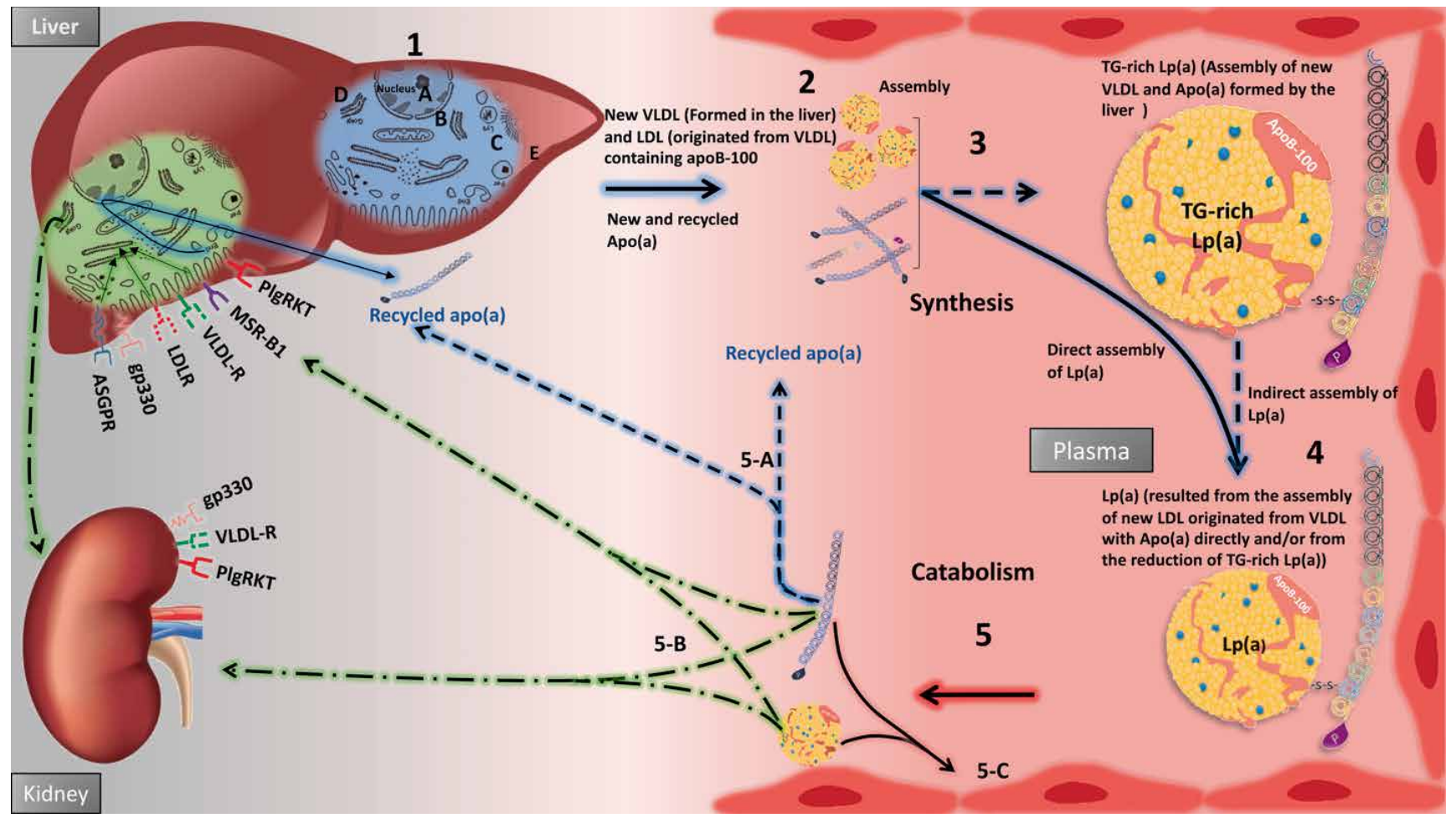

FIgURE 3: Model for the metabolism of apo(a). 1-Lipoprotein (a) production (hepatocyte level). Four stages are likely responsible for apo(a) Lp(a) production in liver cells: (A) transcription of the apo(a) gene and apo(a) mRNA stability in the nucleus; (B) influence of apo(a) translation on the production rate; (c) in the ER, posttranslation modifications and folding of apo(a) kringles; (D) Golgi-specific addition and modification of apo(a) carbohydrates; and (E) transport to the cell surface. 2-Assembly of Lp(a): The site of Lp(a) assembly is controversial. (A) cell surface. (B) The space of Disse. (C) Plasma. 3-Apo(a) associates with a recently made TG-abundant molecule to form Lp(a) with VLDL properties and/or with a cholesterol-abundant molecule with LDL properties. 4-TG-abundant Lp(a) may be transformed into a cholesterolabundant molecule with LDL properties. 5-Catabolism and clearance: The two Lp(a) components become separated. The generation of apo(a) fragments is most likely from proteolytic cleavage by elastases or metalloproteinases secreted by cells in the arterial wall. (5-A) This permits apo(a) to unite the apo(a) pool recently produced by the hepatocytes. (5-B) Hepatocyte internalization and uptake by megalin, gp330 receptor, macrophage scavenger receptor-BI, lipoprotein receptor, VLDL receptor, PlgRKT receptor, asialoglycoprotein receptor (ASGPR), and LDLR. (5-B) Kidney cellular internalization and uptake. (5-C) Vascular wall deposition. Solid lines represent metabolic pathways; dotted lines represent hypothesized metabolic pathways.

Understanding whether apo(a) binds to LDL within liver cells before or after secretion to the plasma and which apo-B100 containing lipoprotein is involved in $\mathrm{Lp}(\mathrm{a})$ assembly should be the focus of future studies to develop new Lp(a)-lowering therapies.

\section{Catabolism}

$\mathrm{Lp}$ (a) clearance is still one of the most fundamental targets of therapies to treat elevated plasma $\mathrm{Lp}(\mathrm{a})$. Unfortunately, little is known about the dominant sites and processes accountable for the removal of $\mathrm{Lp}(\mathrm{a})$ from circulation: scientists debate between the liver and kidneys as the dominant clearance sites. The spleen and the muscles may also play a modest role in the clearance process [36]. Numerous evidence from in vivo studies suggests that the variations in Lp(a) size and plasma concentration are related to apo(a) production rate and size [52] rather than on its very slow clearance rate $[13,26,30,31]$. According to Diffenderfer and colleagues [46], apo(a) requires twice the residency time (11 days) required by apo-B100 (4 days), supporting the notion that the apo(a) and apo-B100 components of $\operatorname{Lp}(\mathrm{a})$ in circulation are not removed from the bloodstream as a unit in humans.

4.1. The Liver. The unique duality of the $\mathrm{Lp}(\mathrm{a})$ molecule's structure allows $\mathrm{Lp}(\mathrm{a})$ to be recognized by multiple LDL and PLG receptors. It was initially thought that LDL receptor (LDLR) in the liver is responsible for the degradation of Lp(a). However, there is evidence that LDLR has minimal or no effect on Lp(a) catabolism [20]. Many kinetic studies have reported that $\mathrm{Lp}(\mathrm{a})$ has a longer circulating time than does LDL-C due to the small affinity of Lp(a) for LDLR [17, 20]. This low affinity occurs because the apo(a) component interferes with the positioning of the LDLR [17]. Second, many clinical studies have reported that increasing LDLR expression by using statins rather than proprotein convertase subtilisin/kexin type 9 (PCSK9) inhibitors does not lower Lp(a) levels; however, PCSK9 inhibitor does [17, 53]. Other receptors, such as Megalin, gp330 receptor [53], macrophage scavenger receptor-BI [54], lipoprotein receptor (LRP-1) [55], VLDL receptor [46], and galactose-specific asialoglycoprotein receptor (ASGPR) [56] show affinity for $\mathrm{Lp}(\mathrm{a})$ and may be involved in $\mathrm{Lp}(\mathrm{a})$ internalization and clearance (see Figure 3). 
The most novel clearance mechanism was presented recently by Sharma and colleagues [50] and involves PLG receptors PlgRKT and proteolytic cleavage and recycling of apo(a) Apparently, PlgRKT is responsible for the uptake and internalization of both circulating $\operatorname{Lp}(\mathrm{a})$ and $\operatorname{apo}(\mathrm{a})$ to the $\mathrm{Rab}^{+}$early endosome. Then, these researchers determined that the apo(a) component of $\operatorname{Lp}(\mathrm{a})$ is trafficked to the Golgi network and released via the Rab $11^{+}$endosome, which subsequently promotes the re-excretion of apo(a) to circulation and the trafficking of the LDL component to the lysosome for degradation [50]. This mechanism suggests that Lp(a) has a longer plasma residence time in circulation than does LDL [17] and support the theory that the liver is the final clearance organ for apo(a) if this component is not reassembled back into $\mathrm{Lp}(\mathrm{a})[50]$.

4.2. The Kidneys. Several in vivo studies have reported that the kidney plays a valuable role in Lp(a) metabolism [57, 58]. An important report has shown that $L p(a)$ levels are elevated and its clearance rate is lower in patients with endstage renal disease undergoing hemodialysis. Urinary apo(a) levels significantly decrease once the glomerular filtration rate becomes $<70 \mathrm{~mL} / \mathrm{min}[59,60]$. Another important study used an in vivo approach by measuring $\mathrm{Lp}$ (a) plasma concentrations simultaneously in the ascending aorta and renal vein of one hundred patients undergoing coronary angiography or coronary angioplasty [61]. Lp(a) concentrations changed remarkably between the two vessels even after correcting for hemoconcentration, corresponding to a mean arteriovenous difference of $-9 \%$ in the arterial concentration [61]. These results suggest that the atherogenic $\mathrm{Lp}(\mathrm{a})$ molecules are taken up by the kidney from renal circulation [61]. In familial hypercholesterolemia $(\mathrm{FH})$ patients, LDL apheresis lessened plasma $\mathrm{Lp}$ (a) concentrations by up to $75 \%$ with an associated abrupt $45 \%$ decrease in urinary apo(a) [62]. The kidneys share with the liver some of the important receptors that show affinity for Lp(a) uptake, e.g., PlgRKT, Megalin, gp330 receptor, and VLDL receptor [46].

\section{Physiological Functions of $\operatorname{Lp}(\mathbf{a})$}

5.1. The Role of $L p(a)$ in Angiogenesis and Tumor Growth. Several studies have reported that $\mathrm{Lp}(\mathrm{a})$ plays a significant role in angiogenesis and tumor growth [63-65]. The similarity between Lp(a) and PLG may decrease the activation of the proteases, which is mandatory for the activation of MMPs and the subsequent activation of angiogenesis [63]. An animal study conducted by Kim et al. [64] reported that Lp(a) plays a significant role in angiogenesis and tumor growth. These researchers demonstrated that recombined kringle fragments derived from apo(a), called rhLK68, significantly inhibit angiogenesis and angiogenesis-dependent tumor growth, but interfere with basic fibroblast growth factor (bFGF)-stimulated/mitogen-activated protein kinase (MAPK) signaling pathway in endothelial cells [64]. Furthermore, another study proved that apo(a) and its components present in the urine are favorably efficient inhibitors in tube forming assays, in vitro surrogate tests for angiogenesis [65]. On the other hand, other studies reported centenarians who did not suffer from CVD, suggesting that $\mathrm{Lp}(\mathrm{a})$ may also play a protective role against cancers $[34,66,67]$.

5.2. Acute-Phase Reactant. Many studies have reported that $\mathrm{Lp}(\mathrm{a})$ levels increase in patients with acute pathologies, such as myocardial infarction, inflammatory bowel disease, and gallbladder fistula [21, 68-70]. One study exposed nine subjects with plasma $\mathrm{Lp}(\mathrm{a})$ concentrations between 64 and $177 \mathrm{mg} / \mathrm{L}$ to a single intravenous infusion of bisphosphonates previously liquefied in $250 \mathrm{~mL}$ of saline; these subjects showed a substantial increase in $\operatorname{Lp}(\mathrm{a}), \mathrm{ESR}$, and CRP two days after intervention [71]. Moreover, Ramharack et al. [72] reported that modulation of $\mathrm{Lp}(\mathrm{a})$ by cytokines resulted in some significant changes in $\mathrm{Lp}(\mathrm{a})$ concentration in primary monkey hepatocytes. In this study, treatment with IL-6, the primary mediator of acute-phase responses, resulted in a marked two- to fourfold increase in $\mathrm{Lp}$ (a) concentration and mRNA expression in hepatocyte culture. Therefore, the inflammatory status should always be considered when interpreting $\mathrm{Lp}(\mathrm{a})$ assays results $[21,71,72]$.

\subsection{Binding and Carrying of Oxidized Phospholipids and LP-}

PLA2. Oxidized phospholipids (OxPLs) play a fundamental role in the early stages of atherosclerosis; they elicit robust proinflammatory responses in murine macrophages and monocytes and are capable of stimulating proinflammatory genes, leading to vascular inflammation [73]. Several studies have reported that OxPLs usually form on oxidizing LDL-C and apoptotic cell membranes and are released into circulation afterward [74-76]. However, another important study suggested that $\mathrm{Lp}(\mathrm{a})$ and OxPLs would associate at the hepatocyte level and not in circulation [77]. Evidence from several studies has shown that $\operatorname{Lp}(a)$ has a unique protective physiological function, which is binding, carrying, and promoting the clearance of OxPLs $[74,75]$. This occurs through the formation of a covalent bond between the KIV of the apo(a) fragment of Lp(a) and OxPLs [78].

5.4. Wound Healing. Wound healing is achieved by multiple complex processes. Many investigators have reported the positive role of $\operatorname{Lp}(\mathrm{a})$ in wound healing $[20,21,79]$. Yano et al. [79] measured the presence of $\mathrm{Lp}(\mathrm{a})$ in tissue during healing. They observed markedly positive staining of $\mathrm{Lp}(\mathrm{a})$ in healing tissues, especially in the fibrous cap surface, endothelial cells of small vessels, and the extracellular space [79], in the second stage of wound healing. Based on this evidence and given that $\mathrm{Lp}$ (a) levels are genetically determined and do not change due to diet or environmental factors, $\mathrm{Lp}(\mathrm{a})$ might be a considerable source of cholesterol for use in tissue regeneration and repair.

5.5. Fibrinolysis. Apo(a) isoforms share substantial structural and functional homology with PLG, the principal component of the fibrinolytic pathway, which is converted to plasmin for fibrinolysis [63]. This homology allows apo(a) to compete with PLG for fibrin affinity sites, as small apo(a) isoforms have a higher affinity for fibrin than do large apo(a) isoforms [80]. Additionally, Lp(a) stimulates the synthesis of PLG activator 


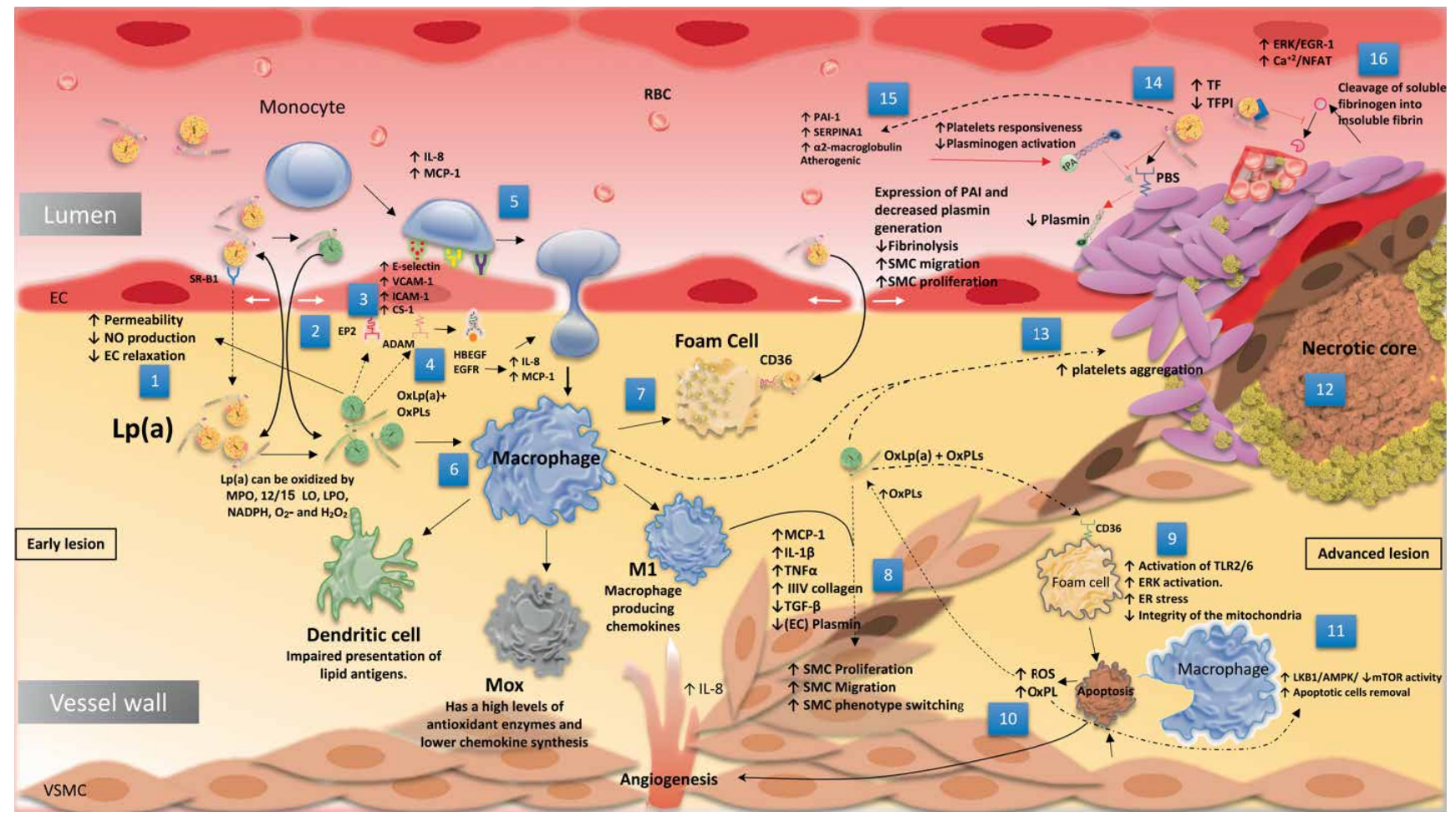

FIGURE 4: Different theories of how Lp(a) causes atherosclerosis. Early lesions (1) Lp(a) enters the vascular wall and is oxidized by MPO, 12/15 LO, LPO, NADPH, $\mathrm{O}_{2}^{-}$, and $\mathrm{H}_{2} \mathrm{O}_{2}$. (2) OxLp(a) and OxPLs constitute a substantial increase in monolayer permeability, resulting in increased Lp(a) and LDL entry into the vascular wall. (3) OxLp(a) and OxPLs bind to the E-type prostaglandin receptor (EP2) receptor, causing deposition of connecting segment 1 (CS-1). Additionally, OxLp(a) stimulates the expression of cell adhesion molecules (ICAM, VCAM E-selectin) that bind to monocytes on the endothelial cell surface. (4) OxLp(a) may also activate specific disintegrin and metalloproteinases (ADAMs) to cause the release of active heparin binding epidermal growth factor (HBEGF) and activation of epidermal growth factor receptor (EGFR) and vascular endothelial growth factor receptor 2 (VEGFR2), causing IL-8 and monocyte chemotactic protein (MCP)-1 production. (5) These chemokines simplify access of the attracted monocytes to the artery wall. (6) OxPL build-up causes monocytes to differentiate into M1, dendritic cells, Mox cells, and foam cells. Advanced lesions (7) macrophages engulf OxLp(a) through its scavenger receptor CD36 to form the foam cell. (8) Ox-Lp(a) and $\operatorname{Lp}(\mathrm{a})$ also induce aberrant proliferation, migration, and phenotype switching of smooth muscle cells (SMCs). (9) OxLp(a) stimulates CD36 to activate TLR2/6, which activates ERK and results in ER stress-induced loss of integrity of the mitochondria, which eventually leads to apoptosis. (10) Apoptotic cells provide more OxPLs and stimulate angiogenesis. (11) OxLp(a) may stimulate LKB1/AMPK/ mTOR activity and induce apoptotic cell removal by macrophages. (12) Necrotic core formation and vessel wall rupture. (13) Macrophage and OxLp(a) cause increased platelet aggregation. (14) Apo(a) binding to PLG binding sites blocks the interaction between PLG and tissue PLG activator (tPA). (15) Lp(a) increases the production and activity of tPA inhibitor-1 (PAI-1), which eventually leads to a decrease in fibrinolysis (16). Lp(a) increases the expression of TF and inhibits the potent inhibitory effect of tissue factor pathway inhibitor (TFPI), which leads to thrombosis. Dotted lines: hypothesized pathways.

inhibitor-1 (PAI-1) to inhibit tPA and urinary-type (u-PA) PLG activators and consequently regulate PLG activation to plasmin [81]. These data shed light on the potential physiological role of Lp(a) in fibrinolysis, by which Lp(a) could give the injured tissue enough time to heal and regenerate.

\section{The Pathogenicity of $\operatorname{Lp}(\mathbf{a})$}

Since the discovery of $\operatorname{Lp}(\mathrm{a})$, many basic scientists and clinicians have dedicated their work to explaining the hidden mechanisms that lead $\mathrm{Lp}(\mathrm{a})$ to cause atherosclerosis. The duality and uniqueness of $\mathrm{Lp}(\mathrm{a})$, which make $\mathrm{Lp}(\mathrm{a})$ homologous to both LDL-C and PLG, most likely underlie the different but related atherosclerosis mechanism theories. Most importantly, Lp(a) transmits all of the harmful atherogenic characteristics of LDL units, incorporating their tendency to oxidize before and after entry into the subintimal layer of the vessel walls and creating extremely proinflammatory oxidized $\mathrm{Lp}(\mathrm{a})$ [OxLp(a)] [17]. In fact, basic medical scientists and clinicians consider $\mathrm{Lp}(\mathrm{a}) \mathrm{far}$ more dangerous than LDL due to the presence of an apo(a) component within $\operatorname{Lp}(\mathrm{a})$. In this part of the review, we will discuss the different theories of how $\operatorname{Lp}(\mathrm{a})$ causes atherosclerosis. These different theories are summarized in Figure 4.

6.1. The Entry of $L p(a)$ into the Vascular Wall. Numerous in vivo kinetic studies have shown that radiolabeled human $\mathrm{Lp}$ (a) enters the intima at a similar rate as does LDL-C in normal and atherosclerotic vessels [82], similar to other lipoproteins, through modest molecular filtering without any receptors [83]. However, this entry depends on lipoprotein plasma concentrations, lipoprotein unit size, blood pressure, vessel wall permeability and $\mathrm{Lp}(\mathrm{a})$ residence time [82]. LDL-C entry into and accumulation in weak but normal vessels begin 
when LDL-C reaches a certain threshold as low as $60 \mathrm{mg} / \mathrm{dL}$ [84]. $L p(a)$, on the other hand, is present in dysfunctional atherosclerotic but not normal vessel walls, and these cells exhibit proinflammatory attributes, which suggests that $\mathrm{Lp}(\mathrm{a})$ plays a role later in the atherosclerotic process after lesions have developed [33]. For instance, Nielsen et al. [85] showed that balloon injury of the thoracic aorta of rabbits leads to accelerated accumulation of radiolabeled $\mathrm{Lp}(\mathrm{a})$ in comparison to radiolabeled LDL-C in the balloon-injured intimal wall [85]. Additionally, the loss rate of $\operatorname{Lp}(\mathrm{a})$ decreased more than that of LDL-C in atherosclerotic vessels [86]. However, this information does not explain why Lp(a) preferentially traps and accumulates at greater rates than does LDL-C. Recently, many researchers have suggested that this phenomenon occurs due to the long residency time for $\mathrm{Lp}(\mathrm{a})$ causes atherosclerosis. These different the long residency time for $\mathrm{Lp}(\mathrm{a})$ in comparison to that for LDL-C [83]. This long residency might be due to the enhanced and selective binding capacity of the abundant LBS in the apo(a) fragment of Lp(a) to the matrix intima and small blood clots (fibrin and glycosaminoglycan) in the injured vascular wall [83]. Additionally, this residency might be due to the recycling effect of apo(a) [50]. In fact, the presence of the LBS of Lp(a) was shown to be associated with potent focal deposition of $\operatorname{Lp}(\mathrm{a})$ in the vascular endothelial wall [87]. The mutation affecting the LBS of Lp(a) of $\mathrm{KIV}_{10}$ decreases the affinity of $\operatorname{Lp}(\mathrm{a})$ to the endothelial wall [88]. Indeed, this information reflects the importance of the role of apo(a) LBS in atherosclerosis pathogenicity. Additionally, under inflammation, leukocytes enhance the persistence and localization of $\mathrm{Lp}(\mathrm{a})$ by releasing a polypeptide named defensing [89]. Finally, in a recent study, scavenger receptor class B type 1 (SR-B1) was shown to transport LDL across the endothelial cell monolayer and thereby governed the transcytosis of LDL by the help of DOCK 4 and the buildup of LDL by artery wall macrophages [90]. This study will shed light on the role of SR-B1 on $\mathrm{Lp}(\mathrm{a})$ recruitment molecules to the endothelial wall.

\subsection{Pro-Inflammatory and Proatherogenic Effects of}

$L p(a)$. Although there are abundant data confirming that inflammation could elevate plasma $\mathrm{Lp}(\mathrm{a})$ concentrations, data have surfaced indicating that the presence of $\mathrm{Lp}(\mathrm{a})$, particularly its apo(a) fragment, causes vascular inflammation $[18,70,73$, $74,91]$. After Lp(a) enters the vessel's walls, it undergoes some oxidation and modification processes. This oxidative effect occurs as a repercussion of existing in an aerobic environment. Nicotinamide adenine dinucleotide phosphate (NADPH) oxidase and myeloperoxidase (MPO) play a vital role in the oxidation of $L p(a)$ by producing reactive oxygen species (ROS). The contact of lipoproteins with lipoxygenase (LPO) or ROS such as superoxide anion and hydrogen peroxide produces miscellaneous OxPL types that commence and augment the inflammatory response [92]. The oxidation and modification processes of $\operatorname{Lp}(\mathrm{a})$ influence its atherogenic characteristics by altering their catabolism to alter the catabolic rate, vessel wall retention, uptake by macrophages, and foam cell formation [93]. One of the significant modifications caused by oxidation is the alteration of receptor identification [94]. Thus, receptors no longer have the ability to identify the oxidized lipoproteins [94]. Subsequently, OxLp(a) triggers a sequence of pro-inflammatory events leading to the development and progression of atherosclerosis [73, 95]. OxLp(a) is then trapped within the intimal layer of the injured vessel, leading to its degradation by lipoprotein lipase, which liberates free fatty acids and monoacylglycerols, resulting in even more local inflammation [73]. It is worth mentioning that the diacylated and triacylated lipoproteins can be identified by Toll-like receptors (TLR-4) and pattern-recognition receptors (PPRs), which usually respond to attacking microorganisms and activate the inflammatory response [73, 96-98].

6.2.1. Role of the Oxidized Phospholipids. One of the key constituents found both in the lipid phase and covalently bound to $\operatorname{OxLp}(\mathrm{a})$ in atherosclerotic lesion is OxPLs. However, atherosclerotic lesions are not the only locations where OxPLs are formed. Apoptosis of various cell types has been shown to be associated with OxPLs generated by NADPH oxidase for clearance by macrophages [96]. Thus, apoptotic cells are another source of OxPLs and may contribute to even more vessel inflammation and atherosclerosis $[74,75,96]$. A wealth of data from papers published in the last decade have documented the regulatory effect of phosphocholine (PC)-containing OxPLs on endothelial cell and macrophage function $[18,49,51,53$, $75,78,99]$. Moreover, abundant evidence has suggested that proinflammatory OxPLs are crucial contributors to the early stages of atherogenesis, such as adhesion molecule expression and immune system activation [100]. Additionally, OxPLs might play an important role in the late stages of atherogenesis, such as platelet aggregation and plaque disruption [100]. Furthermore, exposure of endothelial cells to OxPLs likewise reduces their production of nitric oxide, a crucial arbitrator of vascular wall relaxation [100]. Although OxPLs have some protective effects, such as the activation of prostaglandin E2 production and heme oxygenase 1 (HO-1) formation, OxPLs strongly accumulate under high concentrations of atherosclerotic lesions, which led us to conclude that the OxPL molecule is an atherosclerosis promotor $[96,99]$. In 2008, Bergmark et al. [75] showed that among all apo-B100containing lipoproteins, only $\mathrm{Lp}(\mathrm{a})$ preferentially scavenges and carries OxPLs for clearance through a covalent bond with PC-containing OxPLs in humans. This might be because Lp(a) contains the Lp-PLA $A_{2}$ enzyme, which is responsible for the cleavage of OxPL for degradation and platelet activating factor (PAF) catabolism [29]. Unfortunately, this protective effect is inversely related to $\mathrm{Lp}(\mathrm{a})$ size [29]. This information led us to believe that the potential protective effect when $L p(a)$ exceeds its normal concentration may become harmful and promote the pro-inflammatory atherogenic impact of OxPLs by delivering it to the injured vessels.

\subsection{The Proposed Mechanisms of Endothelial Dysfunction, Inflammation and Atherosclerosis}

\subsubsection{Endothelial Permeability and Adhesion Molecule} Expression. The OxPLs from the apo(a) fragment of OxLp(a) build up in the vascular wall and activate various cell types to express a specific set of proteins that may be involved in the inflammatory reaction through several signaling 
pathways in endothelial cells and macrophages [96]. The high concentration of OxPLs delivered under high levels of OxLp(a) and apo(a) make the endothelial cell monolayer permeable due to the activation of the Src kinase pathway, which phosphorylates vascular endothelial cadherin (VEcadherin) (an essential protein for barrier function) [101]. VE-cadherin phosphorylation leads to disassociation of $\beta$ catenin and paxillin and thus disrupts the cell-cell junction complexes [101]. Another mechanism by which OxLp(a) with OxPLs disrupts the endothelial monolayer involves vascular endothelial growth factor receptor 2 (VEGFR2) activation. VEGFR2 activation subsequently leads to increased Rho/ Rho kinase activation, which triggers the activation of myosin light chain (MLC) phosphorylation by $\mathrm{Ca}^{2+} /$ calmodulinactivated MLC kinase (MLCK) [102] and inactivation of MLC phosphatase by direct phosphorylation of its $130-\mathrm{kDa}$ regulatory subunit (MYPT1) [103]. This mechanism leads to the stimulation of actomyosin contractility, eventual endothelial cell retraction and the creation of openings between endothelial cells [104]. Additionally, OxPLs mediate occludin expression and phosphorylation in vascular endothelial cells, which lead to decreased tight junction interactions, increased permeability of the endothelial cells [105], and increased accumulation of additional $\mathrm{Lp}(\mathrm{a})$. Adhesion molecules play a major role in this mechanism. The interaction of OxPLs with the E-type prostaglandin receptor (EP2) causes an increase in cyclic AMP (cAMP) [106]. Subsequently, cAMP increases R-Ras activation by inhibiting $\mathrm{H}$-Ras activation [106]. This step leads to the stimulation of phosphoinositide 3 kinase (PI3K), which subsequently leads to $\alpha_{5} \beta_{1}$ stimulation on endothelial cells [107]. This causes the buildup of the connecting segment 1 (CS-1) fibronectin, an essential adhesion molecule associated with OxPL, on the apical surface of endothelial cells that binds the attracted monocytes [107]. It is worth mentioning that the association between OxPLs and vascular cell adhesion molecule-1 (VCAM-1) is modest and not detected in large vessels [108]. Indeed, other studies have reported that there is a calcium-dependent interaction of Lp(a) with cultured human coronary artery endothelial cells that does not appear to involve any of the apo(a) LBS that induce efficient surface expression of VCAM-1 and E-selectin adhesion molecules [109]. Moreover, several lines of evidence have shown that OxLp(a) could increase the expression of P-selectin and intercellular adhesion molecule-1 (ICAM-1) in cultured human umbilical vein endothelial cells and suggest its important role in atherogenesis $[110,111]$.

6.3.2. Cytokine Production. IL-8 and chemoattractant molecule 1 (MCP-1) are the chemokines that are responsible for facilitating and guiding the monocyte diapedeses between endothelial cells to infiltrate into the tunica intima or innermost layer of the vascular arterial wall [112]. OxPLs could rapidly induce OxPL MAPK phosphatase 1 (MKP1), thereby stimulating the production of MCP-1 [113]. OxPLs also activate metalloproteinases such as disintegrin and metalloproteinase 10 (ADAM 10) and disintegrin and metalloproteinase with thrombospondin motifs 4 (ADAMTS4), which present on the endothelial cell surface [114]. This metalloproteinase activation leads to activation of heparin-binding EGF-like growth factor
(HBEGF), which attaches to epidermal growth factor receptor (EGFR) to induce IL-8 synthesis $[99,114]$. OxPLs also activate the 15-Lox1-15(S)-HETE axis, which leads to the production of ROS and thereby activates EGFR. EGFR then stimulates signal transducer and activator of transcription 3 (STAT3) phosphorylation through the activation of Src kinase, which eventually leads to MCP-1 expression and production [115]. Additionally, OxPLs elevate cytosolic calcium $\left(\mathrm{Ca}^{2+}\right)$ levels, which are considered an initiator of many signaling pathways. Including the activation of peroxisome proliferator-activated receptor $\alpha$ (PPAR $\alpha$ ), which eventually leads to the expression of IL-8 and MCP-1 [116-118]. OxPLs could also activate the VEGFR2 pathway, leading to IL-8 and MCP-1 production. In contrast, $\mathrm{Lp}(\mathrm{a})$ and its pathogenic fragment apo(a) may independently induce chemoattraction for monocyte cells through a cGMP-dependent pathway [119] and by binding and carrying MCP-1 from the circulation to the vascular wall and may mediate chemoattraction [120]. Finally, Sotiriou et al. [121] reported that apo(a) interaction with $\beta 2$-integrin Mac-1 promotes the adhesion of monocytes and their transendothelial migration in a Mac-1-dependent manner, especially in the presence of homocysteine.

According to Lee et al. [99], following the entry of monocytes into the intimal wall, the newly resident monocytes differentiate into several phenotypes of macrophages in the nascent atheroma. This differentiation occurs due to the activation of TLR-2, TLR-4, CD36, and PAF by OxPLs. The first phenotype of the newly differentiated macrophages is chemokine-producing M1 macrophage. It secretes additional MCP-1, macrophage inhibitor protein-2 (MIP-2), IL-1 beta (IL-1 $\beta$ ), IL-12, inducible nitric oxide synthase (iNOS), tumor necrosis factor $(\mathrm{TNF} \alpha)$ and regulated upon activation, normal T-cell expressed, and secreted (RANTES) [91, 99, 122]. The Mox phenotype, which is characterized by antioxidant Nrf2dependent gene expression may play a role in atherosclerosis [122]. Macrophages could also differentiate into dendritic cells that are not fully functional due to OxPL epigenetic mechanisms [123]. Lastly, the foam cell phenotype is formed by the activation of CD36. CD36 acts as a scavenger receptor and signaling mediator [124]. The foam cell signaling pathway triggers tyrosine protein kinase Lyn/Fyn followed by the stimulation of Vav group proteins, which are cytoplasmic guanine nucleotide exchange factors (GEFs) [99]. Interaction of Vav proteins with dynamin-2/PLC $\gamma$ generates $\mathrm{Ca}^{2+}$ flux. Increased $\mathrm{Ca}^{2+}$ concentration leads to OxLp(a) internalization and foam cell formation [125] (which are hallmarks of early atherosclerotic lesions) [112].

6.3.3. Vascular Smooth Muscles. One of the key features of an advanced atherosclerotic lesion is pathological vascular wall remodeling [126]. Vascular wall remodeling involves VSMC phenotypic switching and endothelial barrier dysfunction. Alexander et al. [127] defined phenotypic switching "as a switch between a contractile to a synthetic state (macrophagelike) through repression of the SMC-selective contractile/ cytoskeletal proteins that mark differentiated SMCs and concomitant increases in proliferation, migration, and matrix synthesis." The VSMC differentiation marker includes smooth muscle (SM) actin $\alpha$, SM myosin heavy chain, myocardin, and 
other components [127]. The goal of vascular SM remodeling in atherogenesis is to shield the foam cells that assemble under the endothelium and to promote the formation of a stable plaque with a thick fibrous cap, thereby protecting against plaque rupture and thrombosis [112, 128]. However, if the atherogenic stimuli persevere over the years, as they often do, the reparative response may become harmful, narrow the vascular lumen, reduce blood flow, and result in eventual ischemia [129].

Numerous previous studies have verified that human $\mathrm{Lp}(\mathrm{a})$, apo(a), and OxPLs promote the phenotypic switching, proliferation, and migration of VSMCs in atherosclerotic lesions [130]. OxPLs have been shown to increase MCP-1, IL- $1 \beta$, and TNF $\alpha$ production via macrophage foam cells, which leads to an increase in the inflammatory state of VSMCs by promoting the production of IL- 6 and multiple MMPs [109, 126]. IL- $1 \beta$ also modulates the VSMC phenotype to a distinct inflammatory phenotype through nuclear factor light-chainenhancer of activated B cells (NF- $\kappa B$ )-dependent mechanisms [127]. Another mechanism by which $\operatorname{OxLp}(a)$, native Lp(a), and OxPLs mediate VSMC phenotypic switching involves the phosphorylation of extracellular signal-regulated kinase (ERK) [131], which leads to the activation of ETS-like transcription factor 1 (Elk-1), eventually repressing the $\mathrm{SM} \alpha$-actin gene and SM heavy chain marker [132]. Additionally, OxPLs might suppress the SM $\alpha$-actin gene through Krüppel-like factor 4 (Klf4), which is involved in most phenotypic switching pathways [133] and eventually binds to histone deacetylases (HDACs), inhibiting the transcription of actin [132-134]. Furthermore, several studies have shown that apo(a) inhibits transforming growth factor- $\beta$ (TGF- $\beta$ ), which is a cytokine involved in the maintenance of normal endothelial and SMC phenotypes and functions [135].

Numerous pathways increase VSMC replication due to exposure to OxPLs and their constituents. Komai et al. [131] showed that Ox-Lp(a) significantly stimulated the growth of human VSMCs in a dose-dependent manner. Moreover, according to Zhao et al. [136], the upregulation of platelet-derived growth factor (PDGF-BB) by the native $\mathrm{Lp}(\mathrm{a})$ and especially $\operatorname{OxLp}(\mathrm{a})$ may be one of the most principal mechanisms accounting for the migration and proliferation of VSMCs and narrowing of the vasculature in atherosclerosis [136]. Another study was able to show that increased atherosclerosis in transgenic rabbits is associated with VSMC proliferation possibly related to impaired fibrinolytic activity by which $\mathrm{Lp}$ (a) build-up may inhibit plasmin and stimulate PAI-1 [130]. OxLp(a) and its OxPLs constituent may also promote VSMC proliferation through the phosphorylation of connexin 43 (Cx43) [137] and activation of galactosyltransferase-2 (GALT2) to produce lactosylceramide (LacCer) and eventually increase c-fos and proliferating cell nuclear antigen (PCNA) [99]. Regarding VSMC migration, the inhibition of TGF- $\beta$ production due to the build-up of $\operatorname{Lp}(\mathrm{a})$ molecules reduces the inhibition of VSMC migration from media to the intima and thereby contributes to atherogenesis [138]. Finally, Ox-Lp(a) may promote VSMC migration through the expression of many extracellular matrix membrane proteins. Most importantly, type IIIV collagen causes OxPLs to activate SP-1 to activate the Klf4 pathway, eventually leading to the migration of VSMCs [139].
6.3.4. Cell Death. In advanced atherosclerotic lesions, macrophages and VSMCs die by programmed cell death (apoptosis) or necrosis. This cellular suicide leads to yet another enigmatic feature of atherosclerotic lesions in that the disintegration of these cells leads to the development of a weakening lipid-rich central pool and delicate and ruptureprone fibrous cap $[123,129]$. OxPLs containing $\operatorname{OxLp}(a)$ and apo(a) largely contribute to cell death. They trigger ER-stressed macrophages mainly through the activation of CD36, TLR2, and TLR-6, which subsequently activate the ERK/MAPK pathway [140]. OxPLs containing Ox-PL(a) are also more potent than oxidized LDL in the generation of ROS and thereby induce apoptosis [141]. ROS generation requires the activation of NADPH oxidase 2 (NOX2) through the activation yet again of the ERK/MAPK pathway [99]. Furthermore, OxLp(a) and its OxPLs may compromise the integrity of the mitochondria to activate the intrinsic apoptotic caspase cascade, thereby inducing macrophage apoptosis [142]. Regarding VSMCs, the results from Loidl and colleagues [128] indicate that activated acid sphingomyelinase is the central mediator in the OxPLtriggered signaling pathway, ultimately leading to apoptosis of VSMCs and causing little but remarkable inflammation [143]. This pathway includes the activation of ceramide to phosphorylate JNK and P38 MAPKs, which have been shown to activate caspase 3 and programmed cell death $[99,143]$.

Afterward, ROS generated due to the build-up of Ox-Lp(a) molecules also activate macrophage autophagy by two direct and indirect pathways. The indirect pathway is mediated by adenosine diphosphate-ribose polymerase-1 (PARP-1), liver kinase B1 (LKB1), adenosine monophosphate-activated protein kinase (AMPK) and the mammalian target of rapamycin (mTOR) signaling pathway. The direct pathway is mediated by LKB1-AMPK-mTOR signaling [144]. Both signaling pathways eventually lead to decreased mTOR activity via decreased phosphorylation of p70S6K and 4EBP1, which can spark macrophage autophagy [144]. Finally, apoptotic cells release phosphatidylserine-containing OxPLs, which stimulate the macrophage uptake of apoptotic cells and may stimulate angiogenesis. At this point, plaques rupture may occur at their shoulder area and is characterized by decreased VSMCs, a thin fibrous cap, a huge necrotic center, and increased macrophage infiltration into the cap.

6.4. Pro-Thrombotic Effect. Following damage to the vessel wall, platelets become triggered and initiate thrombus formation. Fibrin cross-links and stabilizes the clot and then undergoes several fibrinolysis processes [70]. Fibrinolysis is a vastly controlled and restricted process leading to the suspension of fibrin clots and renovation of vascular endothelium [145]. Adsorption of tPA and PLG to the exterior of fibrin permits the creation of plasmin and thus its degradation $[27,145]$. In fact, PLG binding to fibrin alters the protein from a closed to an open conformation [27]. This binding leads to the development of carboxyl-terminal lysine residues, which promote positive feedback in the fibrinolytic cascade [95]. Additionally, it mediates plasmin-mediated alteration of native Glu1-PLG to Lys77-PLG by cleavage of a 76-amino-acid preactivation peptide [95] and thus becomes an improved substrate for tPA [27]. Thereby, plasmin is responsible for the degradation of the 
fibrin molecules within clots. The specific cell surface receptors for PLG are articulated by a wide variety of cells with great density in EC and aid in promoting fibrinolysis and native PLG proteolysis [146, 147]. In fact, they play a major role in accelerating PLG activation and protecting plasmin from inhibition [146]. Moreover, tPA binds to the PLG receptor (annexin 2) at a separate site close to the PLG binding site, leading to a more efficient generation of plasmin.

The structural homology and the abundance of PLG receptors have led to theories about the relationship between $\mathrm{Lp}(\mathrm{a})$ and thrombosis. In fact, as mentioned above, Lp(a) may interfere with the PLG activation ternary complex and lead to competitive interference with PLG and the enhancement of tissue factor (TF) pathways. Moreover, OxPLs may play a vital role in thrombosis. It is worth noting that atherosclerosis and its subsequent thrombosis are mechanistically interlinked. Therefore, further studies are needed to determine whether the direct pro-coagulant antifibrinolytic effect of $L p(a)$ plays a significant role in increasing the risk for atherothrombotic events. $\operatorname{Lp}(\mathrm{a})$ is believed to promote thrombosis by a number of separate but related mechanisms.

6.4.1. Platelet Responsiveness. Platelets are activated on the surface of the injured vascular wall once they are exposed to collagen, leading to the production of dense granules to activate additional new platelets in a positive feedback loop [70]. Aggregation of the platelets then occurs when the $\alpha_{\mathrm{II}} \beta_{3}$ domain of the platelets binds to the attracted fibrinogen molecules, after which clot formation is initiated [148]. Several lines of evidence have associated Lp(a) with enhanced platelet response $[149,150]$. One study suggests that the enhanced responses of platelets may involve proteaseactivated receptor-1 thrombin receptor [149]. Another study suggests that Lp(a) blocks PAF-induced platelet activation in a nonspecific manner[150]. The blocking of $\alpha_{\mathrm{IIb}} \beta_{3}$ activation and fibrinogen attachment to the activated platelets may denote the major mechanism by which Lp(a) blocks PAF-induced platelet aggregation [150]. Moreover, OxLp(a) and OxPLs may be involved in platelet hypersensitivity via the CD36-dependent pathway in a mechanism similar to foam cell formation [151].

\subsubsection{Inhibition of Plasminogen Activation and Plasmin}

Generation. Many reports have revealed that $\mathrm{Lp}(\mathrm{a})$, through its kringles, attaches to fibrin to form the quaternary complex [70] and block new PLG binding and activation at PLG binding sites on fibrin, fibrinogen, and cell surfaces [152]. In fact, $L p(a)$ may attach to carboxyl-terminal lysine residues of fibrin and consequently interfere with fibrinolysis, as apo(a) in $\mathrm{Lp}(\mathrm{a})$ has no catalytic activity [145]. $\mathrm{KIV}_{5-9}$ and kringle $\mathrm{V}$ play a critical role in this mechanism [153]. Lp(a) also inhibits PLG activation by the bacterial activator streptokinase [152]. Moreover, other in vitro and in vivo studies have reported that $\operatorname{Lp}(\mathrm{a})$ and its apo(a) component inhibit the generation of plasmin on the endothelial cell surface with and without interference and tPA binding attenuation [152, 154]. One of the most robust theories behind this phenomenon is that Lp(a) increases the expression of PAI-1, which by definition inhibits the availability of tPA. An important report has shown that PAI-1 inhibits tPA in a protein kinase-C-dependent mechanism $[70,155]$. Another report showed that $L p(a)$ also associates with other prothrombotic proteins, including $\alpha 2$ macroglobulin (A2M) (a plasmin inhibitor) and SERPINA1, a tPA inhibitor [25]. Thus, decreased PLG binding and activation on the cell surface may decrease fibrin degradation and create an antifibrinolytic effect. Finally, the antifibrinolytic effect mainly depends on the size of apo(a) polymorphs [95]; the smaller the apo(a) isoforms are, the higher the antifibrinolytic effect is [156].

6.4.3. Effect of $L p(a)$ on Tissue Factor. TF, which acts as a transmembrane receptor for factor VII/VIIa (FVII/VIIa), is the key cellular motivator of the coagulation protease cascade leading to the triggering of thrombin [157, 158]. It is constitutively expressed by VSMCs, pericytes, and adventitial fibroblasts within the vessel wall and cells surrounding blood vessels [157]. The endothelium physically splits this compelling "activator" from its circulating ligand FVII/FVIIa and blocks inappropriate initiation of the clotting cascade [157]. Damage to the endothelial barrier leads to exposure of extravascular TF and swift initiation of the clotting cascade [157]. Several lines of evidence have shown that $\operatorname{Lp}(\mathrm{a})$ increases the expression of TF and inhibits the potent inhibitory effect of TF pathway inhibitor (TFPI), which eventually lead to thrombosis [159].

6.4.4. Role of $O x L p(a)$ \& OxPLs. Microarray studies demonstrated that OxPL exposure of HAEC from 150 donors controlled the quantities of main thrombogenic molecules [99]. OxPLs drastically downregulated thrombomodulin expression by $40 \%$ while upregulating TF and Serpin B 2 expression by $70 \%$ [99]. The postulated mechanism begins with an elevation of OxPLs, which increases cAMP and cytosolic $\mathrm{Ca}^{2+}$ levels. Cytosolic $\mathrm{Ca}^{2+}$ release plays a vital role in many signaling pathways. Increased $\mathrm{Ca}^{2+}$ levels activate the calcineurin and nuclear factor of activated $\mathrm{T}$ cells (NFAT) pathway, which leads to a shift in and attachment of NFAT to the TF promoter [160]. Moreover, OxPLs activate protein kinase C (PKC), which activates the early growth response protein 1 (EGR-1) pathway [160]. The latter is a transcription factor that usually associates with genes that mediate inflammation and thrombosis. The induction of EGR-1 is mediated by the metenkephalin/extracellular signal-related kinase 1/2 (MEK/ ERK) cascade. EGR-1 and NFAT activation eventually leads to upregulation of TF [160].

6.4.5. Effect of $L p(a)$ on Tissue Factor Pathway Inhibitor. TFPI is a protease inhibitor with three tandem Kunitz-type blocking domains (K1, K2, and, K3) that blocks the TF coagulation cascade [161]. Thus, TFPI strongly blocks the initial steps of the extrinsic coagulation pathway [95]. TFPI is present on endothelial cells, activated monocytes, and platelets [95]. $\mathrm{Lp}(\mathrm{a})$ and OxPLs inhibit the activity of isolated TFPI, which augments unopposed TF effects. The mechanism underlying its inhibitory activity is direct binding to the active TFPI inhibitor domains with much higher affinity than PLG and inactivation of TFPI activity in the presence or absence of physiologic concentrations of PLG [159]. 


\section{Factors that Influence $L p(a)$ Levels in the Blood}

Primarily, the Lp(a) plasma levels are genetically determined. Nonetheless, several factors may increase or decrease the Lp(a) bloodstream levels, as reviewed [36, 63, 162]. For example, chronic liver as well as kidney diseases are associated with plasma $L p(a)$ levels [58, 61, 80, 163-165]. Moreover, as mentioned above, elevated $\mathrm{Lp}$ (a) concentrations are an acute phase reactant, for example, following an inflammatory stimulus, pregnancy, myocardial infarction and other situations [162, 166]. These augmented $L p(a)$ levels stabilize subsequently when the trigger signal of the acute phase withdraws [162, 166]. Several studies have examined the relationships between Lp(a) concentration and chronic ethanol consumption. Ethanol has a powerful influence and decrease bloodstream Lp(a) levels up to 60\% [63] in dose-dependent manner independent of the size distribution of apo(a) isoforms [167]. Tobacco smoking reduces plasma $\mathrm{Lp}$ (a) by up to $20 \%$ [168, 169] although tobacco smoking is one of the major risk factors for CVD, increasing plasma TG and lowering HDL-C [170].

Several underlying diseases and the therapeutic administration of hormones affect $\mathrm{Lp}$ (a) plasma levels, partly due to changes occurring in other lipoproteins. For instance, the administration of hormones such as adrenocorticotrophic hormone (ACTH) has a strong effect on Lp(a) levels, decreasing them up to $40 \%$ [63]. Moreover, there are divergent effects of growth hormone (HGH) and IGF on plasma Lp(a) levels [63]. Though HGH significantly increases Lp(a) levels by up to $120 \%$, IGF-I decreases $\mathrm{Lp}(\mathrm{a})$ concentrations by up to $60 \%$ [171]. Insulin inconsistently affects Lp(a) levels [172, 173]. Moreover, male and female sexual steroids affect many parameters of fat metabolism [174]. Anabolic sterols considerably decrease Lp(a) levels up to $70 \%$ [175]. Lastly, Lp(a) levels increase one- to twofold or more during the gestational period and normalize after delivery, during the puerperium period [176]. Other factors influencing $\mathrm{Lp}(\mathrm{a})$ levels are summarized in Table 1.

\section{Lp(a) Measurement}

8.1. Isoform-Dependent vs. Isoform-Independent. There are many structural characteristics of $\operatorname{Lp}(\mathrm{a})$, which, along with the covalent bond of apo(a) with apo-B100, make it peculiar. Additionally, there are strong structural similarities between apo(a) and PLG. Most importantly, the high particle size heterogeneity is associated with the variability in $\mathrm{KIV}_{2}$ repeats. This peculiar structure results in substantial limitations and challenges to standardizing immunological assays, determining appropriate calibrators and selecting reference material, activities that are crucial for analyzing and comparing the results of different studies [19]. There are two categories of immunological assays used to measure $\operatorname{Lp}(\mathrm{a})$ levels. The first category of immunological assays is "isoform-dependent," representing the entire protein mass of $\operatorname{Lp}(\mathrm{a})$, reported in milligrams per (deciliter/liter) [183]. The molecular mass of the apo(a) protein mainly depends on the number of $\mathrm{K}_{\mathrm{IV}}$ motif repeats, with an extremely wide range of 200-800 kilodaltons [39]. There are many concerns related to measuring Lp(a) mass because most antibodies are polyclonal and cross-react with several $\mathrm{K}_{\mathrm{IV} 2}$ repeats. These assays would thus overestimate $\mathrm{Lp}$ (a) concentrations in patients with large apo(a) isoforms and underestimate $\mathrm{Lp}$ (a) concentrations in patients with small apo(a) isoforms [17]. Thus, the impact of the heterogeneity of $\mathrm{Lp}$ (a) mass may lead to underestimation of the relationship between $\mathrm{Lp}(\mathrm{a})$ concentration and CVS risk assessment. The other category is "isoform-independent," an assay that recognizes a unique nonrepeating kringle IV (type 9), and it is reported in units of nanomoles per liter (nmol/L) [11]. Use of the isoform-independent immunological assays is considered the gold standard by the International Federation of Clinical Chemistry and Laboratory Medicine (IFCC) and approved by the World Health Organization (WHO) to measure Lp(a) because in these assays, apo(a) size will not affect the final results [184]. It is worth noting that most previous research used the mass-dependent $\mathrm{mg} / \mathrm{dL}$ instead of $\mathrm{nmol} / \mathrm{L}$. Moreover, many scientists have used a mean conversion factor of $2.4(2.4 \mathrm{nmol} / \mathrm{L}$ to $1 \mathrm{mg} / \mathrm{dL}$ or $10 \mathrm{mg} / \mathrm{L}$ ) to convert mass-based concentrations $(\mathrm{mg} / \mathrm{dL}$ or $\mathrm{mg} / \mathrm{L}$ ) of $\mathrm{Lp}(\mathrm{a})$ to molar concentrations (nmol/L) [185]. However, the $\mathrm{Lp}(\mathrm{a})$ conversion factor, unlike the conversion factors for any analyte with a defined molecular mass, is inaccurate because it ignores the size heterogeneity of apo(a) and should be re-evaluated for accuracy [186]. Moreover, $\mathrm{Lp}$ (a) should be preferably measured in freshly isolated plasma, although most laboratories worldwide use frozen samples, which may lead to inaccurate results [11]. As the efficacy of various new $\mathrm{Lp}(\mathrm{a})$-lowering therapies is currently under intense investigation, it is clear that great consideration must be given to the assay that is used to measure plasma $\mathrm{Lp}(\mathrm{a})$ levels to have an accurate, reproducible, dependable, and standardized quantitation of $\mathrm{Lp}(\mathrm{a})$.

\subsection{Important Considerations}

8.2.1. Friedewald Formula. We use this formula commonly in clinical practice to calculate LDL-C. LDL-C $=\mathrm{TC}-$ (HDL-C + TG/5), where TG/5 represents the cholesterol in VLDL, provided that the plasma TG levels are $<4.5 \mathrm{mmol} / \mathrm{L}$ and that type III dyslipoproteinemia is not present [187]. HDL-C is quantified in the plasma supernatant after the apoB100-containing lipoproteins are precipitated by a polyanion that precisely interacts with the apo-B100 of both $\mathrm{Lp}(\mathrm{a})$ and LDL [187]. Thus, the Friedewald formula overestimates the LDL-C value, which is, in fact, the value LDL-C + Lp(a)-C. This is very crucial because elevated $L p(a)$ levels increase LDL-C thanks to the Friedewald formula and may contribute to the diagnosis of certain diseases, such as $\mathrm{FH}$, which depend clinically on a specific LDL-C threshold.

\section{Screening}

Plasma Lp(a) levels increase soon between after birth until the 7 th postnatal day [188] and reach a constant concentration within a few months of life [189]. In adults, $\mathrm{Lp}$ (a) levels range widely, from $<2$ up to $2500 \mathrm{mg} / \mathrm{L}$ [190]. It used to be thought that there were no differences in $\mathrm{Lp}(\mathrm{a})$ levels associated with gender. However, many studies suggest females are more prone 
TABLE 1: The main factors affecting Lp(a) levels in humans.

\begin{tabular}{|c|c|}
\hline & Increase Lp(a) levels \\
\hline Apo(a) gene & Up to $90 \%$ \\
\hline Acute phase & $\begin{array}{l}\text { Up to two-fold increase in } \mathrm{Lp}(\mathrm{a}) \text { concentrations. Concentrations normalize after the triggering signal for the } \\
\text { acute phase withdraws. The highest upsurge is reported approximately } 6-8 \text { days after the acute event } \\
{[162,166]}\end{array}$ \\
\hline Renal disease & Renal insufficiency and nephrotic syndrome increase $\mathrm{Lp}(\mathrm{a})$ levels up to three-fold $[58,61,163]$ \\
\hline Diabetes mellitus & The increase in $\mathrm{Lp}(\mathrm{a})$ levels in diabetic patients mainly relates to the stage of kidney disease $[172,173]$ \\
\hline Hypothyroidism & Increase in $\mathrm{Lp}(\mathrm{a})$ concentrations was reported [198] \\
\hline Pregnancy & $\begin{array}{l}\text { Up to two- to threefold increase during pregnancy, with highest } L p(a) \text { levels increase seen at the } 20^{\text {th }} \text { week } \\
{[176]}\end{array}$ \\
\hline \multirow[t]{2}{*}{$\mathrm{HGH}$} & Increases $\mathrm{Lp}(\mathrm{a})$ by up to $120 \%[171]$ \\
\hline & Decrease Lp(a) levels \\
\hline Cholestatic liver diseases & Up to $90 \%$. May be due to impairment of Lp(a) production and/or assembly \\
\hline Alcohol consumption & Chronic consumption may reduce plasma $\mathrm{Lp}(\mathrm{a})$ in a dose-dependent manner and up to $60 \%[167,178]$ \\
\hline IGF-1 & Was found to decrease $\mathrm{Lp}(\mathrm{a})$ levels by $60 \%[171]$ \\
\hline Anabolic steroids & Up to $70 \%$ reported $(\mathrm{N} / \mathrm{R})[45,175]$ \\
\hline Testosterone & Only few reported up to $40 \%$ reduction [179] \\
\hline ACTH & Yield reductions of up to $30-40 \%[63]$ \\
\hline Tamoxifen & Anti-estrogen drug that decreases $\mathrm{Lp}(\mathrm{a})$ by $35 \%$ \\
\hline $\mathrm{Ca}^{+2}$ antagonists & Less than $10 \%$ reduction $[180]$ \\
\hline Estrogens & Up to $37 \%$ reported in postmenopausal women receiving HRT (N/R) [45] \\
\hline Progesterone & Low percentage reported \\
\hline Tibolone & Agonist of type I steroid hormone receptor, Leads to $35 \%$ reduction \\
\hline Raloxifene & Estrogen receptor modulator, leads to $35 \%$ reduction \\
\hline Cigarette smoking & Lowers plasma Lp(a) levels by $10-20 \%[168,169]$ \\
\hline Cancer & Tumors of many origins reported up to cause a two-fold increase $[34,66,67]$ \\
\hline Obesity & There is an inverse relationship between weight plasma Lp(a) concentration and obesity [63] \\
\hline Diet & $\begin{array}{l}\text { Majority of the reports have shown no to minimum reduction[181]; however, a defined plant-based diet } \\
{[182] \text { and fish oils were found to reduce plasma Lp(a) by } 10 \%[180]}\end{array}$ \\
\hline
\end{tabular}

to elevated Lp(a) levels than are males [191-193] and that they are especially prone during pregnancy [176]. According to a study of the general population of Copenhagen, the distribution of $\mathrm{Lp}(\mathrm{a})$ levels is positively skewed to the left, with a tail toward the highest levels [194] that represents $20 \%$ of the general population [195]. Moreover, one of the most distinctive features regarding $\mathrm{Lp}(\mathrm{a})$ is that there are significant differences in plasma $\mathrm{Lp}$ (a) levels between different populations and ethnic groups [34]. Lp(a) levels are the lowest in Caucasian patients and highest in patients of African ethnicity. Most studies suggest that the Lp(a) cut-off point for CVD should be equal to or above $500 \mathrm{mg} / \mathrm{L}$, which represents the $80^{\text {th }}$ percentile of the general population distribution for $\operatorname{Lp}(\mathrm{a})$; this value can be rationally proposed to clinicians as an indicator of augmented risk for CVD [19]. Nevertheless, due to the nonexistence of firmly established race-specific clinical cut-off points for $\mathrm{Lp}(\mathrm{a})$ levels in populations other than those of Caucasians, clinicians should exercise their best judgment in the risk assessment of different ethnic groups [19].

Screening for increases in $\mathrm{Lp}(\mathrm{a})$ levels in the general population is still not recommended [11]. Because the majority of circulating $\mathrm{Lp}(\mathrm{a})$ molecules are genetically determined with little effect from diet and environment [196] and because plasma concentrations do not vary considerably around a preset baseline over a lifespan $(<10 \%)$ in any individual, it is logical that this measurement is required only once for screening or diagnostic purposes [196]. Moreover, because Lp(a) level screening is a cost-effective test, it could rationally be added to the lipid profile for first-time patients [17]. Nordestgaard and colleagues [194] recommend that Lp(a) be measured in patients with $\mathrm{FH}$, a strong family history of CVD, a personal history of premature CVD, recurrent CVD despite statin treatment, and an inadequate response to statins. Moreover, $\mathrm{Lp}(\mathrm{a})$ should be measured in patients with $\mathrm{a} \geq 5 \%$ 10 -year risk of fatal CVD according to the European guidelines [197] or $\geq 10 \% 10$-year risk per US guidelines, as well as in patients with a 10-19\% Framingham risk according to 2012 Canadian Cardiovascular Society recommendations [180]. Finally, consideration of repeat measurement is indicated only in individuals treated for high Lp(a) levels [198] (Table 2).

\section{Interventions}

10.1. Diet and Physical Exercise. A healthy diet and regular exercise are recommended for the prevention of coronary artery disease because these practices improve the lipid profile as well as the Framingham risk score [181]. However, their effects on $\operatorname{Lp}(\mathrm{a})$ concentration are completely different. The majority of cross-sectional and interventional studies support the empirical evidence that 
TABLE 2: Whom to screen.

$\mathrm{Lp}$ (a) should be measured once in all subjects at intermediate or high risk of $\mathrm{CVD} / \mathrm{CHD}$ who present with one of the following:

(i) Premature CVD

(ii) Recurrent CVD despite statin treatment

(iii) Familial hypercholesterolemia

(iv) Strong family history of premature CVD and/or elevated $\mathrm{Lp}(\mathrm{a}) \geq 500 \mathrm{mg}$

(v) Recurrent CVD despite optimal lipid-lowering treatment

(vi) $\geq 5 \% 10$-year risk of fetal CVD according to European guidelines

(vii) $\geq 10 \% 10$-year risk of fetal CVD according to US guidelines

(viii) $10-19 \%$ Framingham risk according to the 2012 Canadian Cardiovascular Society recommendations

Repeat measurement is only necessary if treatment for high $\mathrm{Lp}(\mathrm{a})$ levels is initiated in order to evaluate therapeutic response

This table was adopted from [194].

serum $L p(a)$ concentration is regulated independently of diet, other lipoprotein classes, and long-term or acute rigorous physical exercise $[13,181]$, despite these activities producing a favorably improved lipid profile [13, 199]. Conversely, a recent study has shown that a plant-based diet substantially decreased inflammatory biomarkers and atherogenic lipoproteins, including Lp(a) [182].

Although lifestyle factors may not directly impact $\mathrm{Lp}(\mathrm{a})$ levels themselves, the synergistic multiplier effect of high LDL and $\operatorname{Lp}(\mathrm{a})$ concentrations together should be carefully considered. Indeed, studies have shown that in patients with elevated $\mathrm{Lp}$ (a) and LDL-C levels, CVD risk is magnified compared to that in patients with only high LDL-C $[183,200,201]$. Therefore, reducing LDL-C (e.g., via diet) and elevating HDL-C (e.g., via exercise) levels in the bloodstream must be greatly recommended to lessen the synergistic multiplier risk and should always be the core pillar of high Lp(a) CVD preventive care $[13,201]$.

\subsection{Medication}

\subsubsection{Lipid Treatment Essentials}

(1) HMG-CoA Reductase Inhibitors. While 3-hydroxy-3-methyl-glutaryl-coenzyme A (HMG-CoA) reductase inhibitor (aka "statin") intervention is essential in atherosclerosis, the effect of statins on $\mathrm{Lp}(\mathrm{a})$ is controversial. It has been assumed that statins slightly reduce or have no effect on $\operatorname{Lp}(\mathrm{a})$ concentrations because the LDLR may play either no role or an inconsequential role in $\mathrm{Lp}$ (a) clearance. In fact, in patients with $\mathrm{FH}$, statins have been shown to reduce $\mathrm{Lp}(\mathrm{a})$ levels by $17-22 \%[180,202]$. However, recent data from the Justification for the Use of Statins in Prevention: an Intervention Trial Evaluating Rosuvastatin (JUPITER) study showed that HMGCoA reductase inhibitors tended to increase $\mathrm{Lp}(\mathrm{a})$ levels by $10-20 \%[17,203]$. This result could be why some subjects do not usually respond to decreased LDL-C levels by statins, as most of their cholesterol is on $\mathrm{Lp}(\mathrm{a})$ molecules rather than LDL molecules [204] and Lp(a) can surge with statin treatment [17] (Table 3).

\subsubsection{Reducing the Production of Novel Lp(a)}

(1) IONIS-APO(a)-LRx (AKCEA-APO (a)-L $\left.L_{R x}\right)$. IONIS$A P O(a)-L_{R x}$ is a second-generation antisense oligonucleotide (ASO) designed to reduce the synthesis of apo(a) in the liver [17]. IONIS-APO $(a)-L_{R x}$ is a chemically modified oligonucleotide (typically 16-20 nucleotides) [228] targeting hepatic mRNA in the nucleus and in the cytoplasm if mRNA is present in this compartment to lower plasma concentrations of apoB-containing lipoproteins, including Lp(a) [17]. ASOs bind to plasma proteins and enter the liver, where they accumulate intracellularly. Then, ASOs selectively bind mRNAs coding for apo(a) proteins and often cause degradation at Watson-Crick hybridization [228]. Once attached, ASOs can act via a number of mechanisms, but the most common mechanism is the recruitment of RNase H1, an enzyme that degrades apo(a) mRNA in a DNA-RNA-like duplex. The activation of RNase $\mathrm{H} 1$ eventually reduces plasma concentrations of the apo(a) protein or through translational arrest blocks the ribosome $[208,209,229]$. The other mechanisms include the initiation of RNA cleavage through catalytically active ribozymes and RNA interference induced by small interfering RNA (siRNA) molecules [230].

In a recent randomized, double-blind, placebo-controlled, phase I study, 47 healthy individuals aged 18-65 years with $\mathrm{Lp}$ (a) levels of $25 \mathrm{nmol} / \mathrm{L}(100 \mathrm{mg} / \mathrm{L}$ ) or more were randomized to receive one single dose of IONIS-APO(a) at different concentrations $(50-400 \mathrm{mg})$, six consecutive doses at different concentrations or placebo [209]. The multiple-dose treatment produced a substantial dose-dependent reduction in $\mathrm{Lp}(\mathrm{a})$ levels from baseline to the end of the fifth week $(100 \mathrm{mg}: 39.6 \%$, 200 mg: 59.0\%, 300 mg: 77.8\% vs. placebo) [209]. OxPL-apo[a] and OxPL-apoB levels were also significantly lower at week five [209]. In a phase II trial, 64 participants with high Lp(a) levels were randomly assigned treatments $(100 \mathrm{mg}, 200 \mathrm{mg}$, and $300 \mathrm{mg}$ once a week for four weeks each) or injections of saline placebo (once a week for 12 weeks). At day 85/99, participants had mean $\mathrm{Lp}(\mathrm{a})$ reductions between $66.8 \%$ and $71.6 \%$ [208]. Furthermore, this drug significantly decreased the inflammatory properties of monocytes, which, as mentioned before, originate and hasten CVD, in addition to plasma LDL-C [208]. IONIS-APO(a)- $\mathrm{L}_{\mathrm{Rx}}$ also contains an $\mathrm{N}$-acetyl-galactosamine $\left(\mathrm{GalNac}_{3}\right)$-conjugated that is selectively taken up by hepatocytes, with a mean reduction up to $99 \%$ reduction of $L p(a)$ in some patients [17]. These trials showed that IONIS-APO(a)- $\mathrm{L}_{\mathrm{Rx}}$ is a tolerable, potent, and promising selective $\mathrm{Lp}(\mathrm{a})$-lowering drug. It remains to be seen whether IONIS-APO(a)- $\mathrm{L}_{R x}$ will reduce CVD events related to high $\operatorname{Lp}(\mathrm{a})$. Also, It remains to be seen whether newer drugs such as AMG 890 [210] have better efficacy and reduce CVD events significantly.

(2) Mipomersen. To date, only mipomersen, a secondgeneration ASO against the coding region of human apoB mRNA (nucleotides 3249-3269), has been approved by the US FDA as an adjunct to diet and statins for lowering LDL-C, apoB, total cholesterol, and nonHDL-C for the treatment of homozygous FH (HoFH) [211]. Mipomersen also has also significantly decreased $L p(a)$ concentrations $[183,212]$. In four phase III trials, 382 participants receiving maximally tolerated 


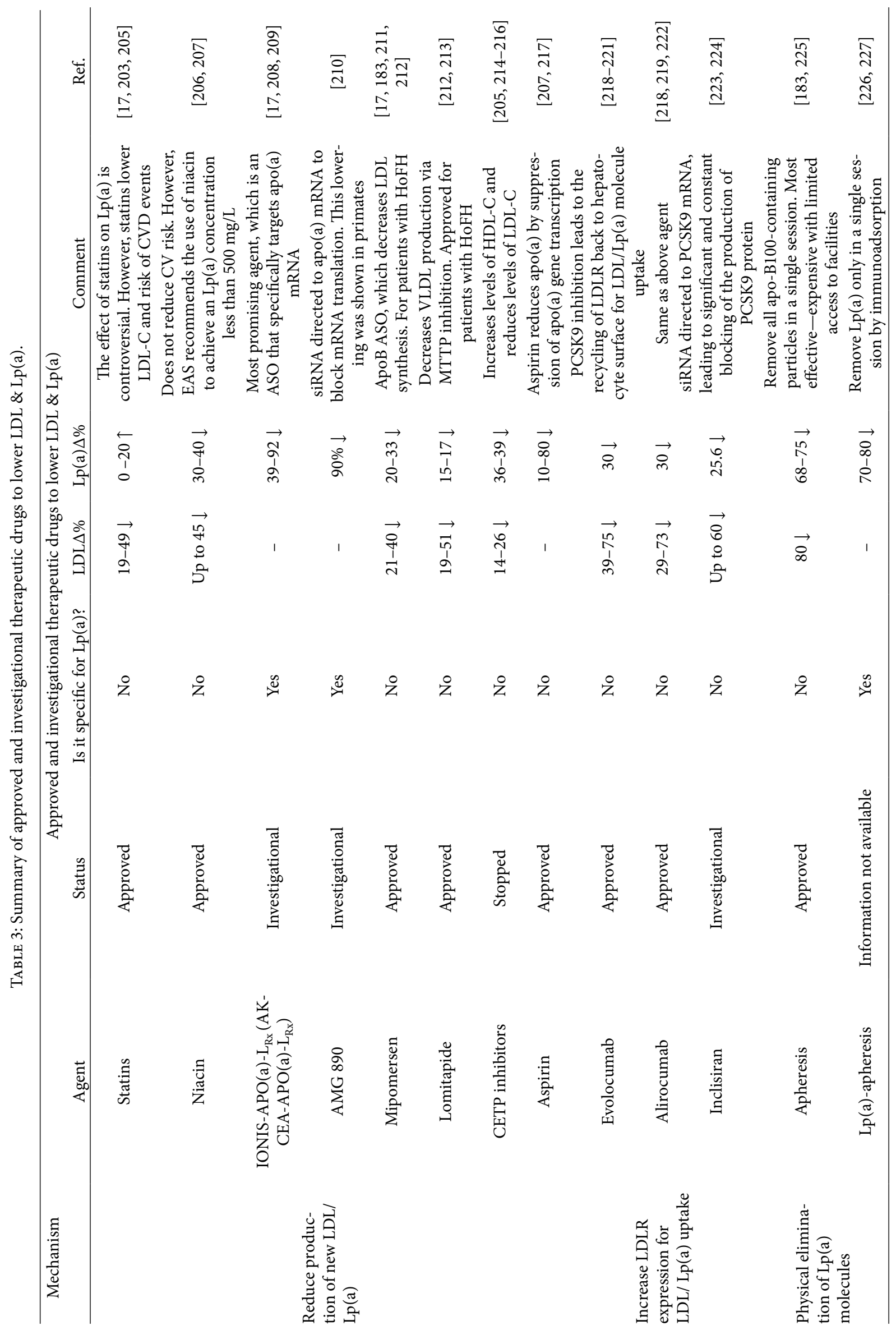


lipid-lowering treatment were randomly allocated to weekly administration of $200 \mathrm{mf}$ of the ASO mipomersen or placebo for 26 weeks [211]. The median percent decrease in Lp(a) concentration at 28 weeks was significantly greater in the mipomersen group than in the Placebo group $(-26.4 \%$ [IQR: -42.8 , -5.4 ] versus $0.0 \%$ [IQR: $-10.7,15.3$ ]; $P<0.001$ ) [211]. However, mipomersen did not affect the production of apo(a), which continued to be released into the plasma as "free" apo(a) [17]. Similar to lomitapide, hepatotoxicity has been observed with mipomersen, and therefore, mipomersen has only been approved for patients with HoFH.

(3) Lomitapide. Lomitapide is an inhibitor or blocker of microsomal TG transfer protein (MTTP), which is an ER-associated protein [212]. It plays a central role in the biosynthesis of lipoproteins by mediating the allocation of neutral lipids (CE and TG) to the new apo-B100 and apo-B48 polypeptides [212], thus promoting the association of VLDL in the liver and chylomicrons in the intestine [212]. Thus, lomitapide does not depend on the functionality of LDL receptors. Lomitapide combined with a low-fat diet and statins substantially and stably lowers LDL-C by $50 \%$ in adult patients with HoFH [213]. In an open-label, phase III study, 29 subjects with $\mathrm{HoFH}$ were enrolled to receive lomitapide for 78 weeks [213]. The median dose of lomitapide was $40 \mathrm{mg}$ per day [213]. The drug produced a $15 \%$ reduction in $\operatorname{Lp}(\mathrm{a})$ concentration at 56 weeks [213]. However, by the end of the study, there was no statistically significant difference in $\mathrm{Lp}(\mathrm{a})$ concentration from the baseline [213].

(4) Niacin. Niacin is considered a broad spectrum hypolipidemic agent [231]. It has an antilipolytic effect, reducing the mobilization of free fatty acids from the adipose tissue to the liver and reducing the trafficking of free fatty acids, which significantly decreases the concentrations of all apo-B - containing lipoproteins from chylomicrons to $\operatorname{Lp}(\mathrm{a})[206,232]$. Niacin also stimulates the degradation of apoB-containing lipoproteins and decreases TG synthesis by inhibiting diacylglycerol acyltransferase-2 [23], an enzyme that catalyzes the final reaction involved in TG production as well as selective inhibition of apoA-I uptake without affecting de novo production [205], which eventually increases HDL-C concentrations [205, 231]. A therapeutic dose of niacin is associated with LDL-C and Lp(a) reduction by approximately $45 \%$ [205] and 20-30\%, respectively, as shown in a meta-analysis of 14 randomized placebo-controlled clinical trials including 9,013 subjects [206], but with detrimental adverse effects. Unfortunately, niacin intervention has not been shown to reduce cardiovascular risk in recent clinical trials [233]. However, in Europe, the use of niacin at a dose of $1-3 \mathrm{~g} /$ day in high-risk patients after suitable LDL-cholesterol reduction is recommended by the European Atherosclerosis Society (EAS) to achieve a $\mathrm{Lp}$ (a) concentration $<500 \mathrm{mg} / \mathrm{L}$ [183]. Finally, it must be noted that clinical research trials on niacin lack reliability with respect to patient assortment, drug dosage, intervention interval, and techniques used for quantifying Lp(a) [234].

(5) Cholesterylester Transfer Protein (CETP) Inhibitors. CETP mediates the exchange of cholesterol esters and TGs of LDL-c and HDL-c. Blocking this transfer with CETP inhibitors increases HDL-C levels and reduces $t$ LDL-C levels [216]. In a study that evaluated the effects of the CETP inhibitor anacetrapib on lipid levels and its safety when administered as single therapy or in ad-on therapy with statins in Japanese patients, intervention as single therapy or coadministered with statins significantly decreased Lp(a) and LDL-C levels and increased HDL-C levels [215]. In a randomized, double-blind, placebo-controlled trial to evaluate the efficacy and safety of anacetrapib in 1623 patients with CHD, intervention consistently decreased $\mathrm{Lp}$ (a) levels by $38.8 \%$ from baseline levels [214]. While CETP inhibitors might significantly improve the lipid profile, no data are available because research activities have been stopped [186].

(6) Aspirin. Aspirin is mainly used for its antithrombotic effect. In 2002, a study evaluated the effect of aspirin treatment on serum concentrations of $\mathrm{Lp}(\mathrm{a})$. Japanese with high $\mathrm{Lp}(\mathrm{a})$ patients $(n=70)$ were recruited and received aspirin $(81 \mathrm{mg} /$ day). Aspirin decreased serum $\operatorname{Lp}(\mathrm{a})$ levels to $\sim 80 \%$ of the baseline values in patients with high Lp(a) levels $(>300 \mathrm{mg} / \mathrm{L}$ ) [217]. Aspirin may reduce apo(a) production in human liver cells by suppressing apo(a) gene transcription [207].

\subsubsection{LDL Receptor Removal or Uptake}

(1) PCSK9 Inhibitors. PCSK9 is a protein involved in regulating LDLR recycling, and it was discovered when investigators found gain-of-function genetic alterations in PCSK9 protein in patients with FH [218]. PCSK9 inhibitors such as evolocumab and alirocumab are fully human monoclonal antibodies that attach to the PCSK9 protein and obstruct its contact with the LDLR, resulting in boosted receptor recycling and LDL clearance [235]. These drugs have been shown to reduce LDL-C by up to $60-70 \%$ [221]. Trials that have observed lipid profiles in patients treated with PCSK9 inhibitors showed reproducible and constant reductions in Lp(a) levels [14]. However, it is unclear whether the Lp(a)-lowering effect could be expected in the early clinical trials. An analysis of data pooled from 1359 patients enrolled in 4 phase II trials assessed the effects of evolocumab on Lp(a) levels. Significant dose-related decreases in Lp(a) levels compared to those under placebo treatment were reported [220]. Evolocumab therapy for 12 weeks significantly decreased Lp(a) levels by $29.5 \%$ (95\% CI: $23.3 \%, 35.7 \%$ ) and $24.5 \%$ (95\% CI: $20.4 \%, 28.7 \%$ ) when given at $140 \mathrm{mg}$ and $420 \mathrm{mg}$ dosed every two and four weeks, respectively [220]. In a pooled data analysis from 3 double-blind, randomized, placebo-controlled, phase II trials, alirocumab at $150 \mathrm{mg}$ every two weeks significantly decreased $\mathrm{Lp}$ (a) levels in patients with hypercholesterolemia [222] from baseline levels compared with those under placebo treatment (30.3\% vs. $0.3 \%, P<0.0001$ ) [222].

(2) Inclisiran. Inclisiran is a long-acting siRNA therapeutic agent that reduces the synthesis of PCSK9 protein, a target for the lowering of LDL-C [223]. The inclisiran molecule follows the ordinary pathway of mRNA interference and PCSK9 silencing via RNA interference [236]. In transgenic mice expressing human PCSK9, inclisiran decreased PCSK9 mRNA concentrations up to $70 \%$ concomitant with up to a $60 \%$ decrease in plasma cholesterol concentrations [236]. In a randomized, single blind, placebo-controlled phase I trial in 
patients with LDL-C levels $\geq 100 \mathrm{mg} / \mathrm{dL}$ and fasting TG levels of $<400 \mathrm{mg} / \mathrm{dL}$, doses of $300 \mathrm{mg}$ or more significantly lowered levels of PCSK9, LDL-C, and Lp(a) by $74.5 \%, 50 \%$, and $48.1 \%$, respectively, for at least six months [223]. In a phase II, double-blind, placebo-controlled, multiple-ascending-dose trial of inclisiran vs. placebo, 501 patients at high risk for CVD and with LDL-C levels $>2.5 \mathrm{mmol} / \mathrm{L}$, or $>1.8 \mathrm{mmol} / \mathrm{L}$ were enrolled in the study [224]. The experimental group that received $200 \mathrm{mg}$ of inclisiran at baseline and after 90 days experienced a persistent decrease in LDL-C and Lp(a) levels by $52.6 \%$ and $25.6 \%$, respectively, at 180 days compared with the values at baseline [224].

10.3. Apheresis. Extracorporeal elimination with apheresis is the most effective, well-tolerated, and approved treatment for lowering $\operatorname{Lp}(\mathrm{a})$ levels $[237,238]$. This process removes all apoB-containing lipoproteins (specifically LDL-C and Lp(a)) from the blood using antibody-coupled columns, precipitation, and complex creation at low $\mathrm{pH}$. Double filtration and direct absorption have been confirmed to lower plasma LDL-c and Lp(a) levels by up to $80 \%$ [63]. A longitudinal cohort trial that evaluated the efficiency of lipid apheresis therapy on Lp(a) concentrations and major adverse coronary events (MACEs) reported a median reduction in $\mathrm{Lp}(\mathrm{a})$ levels of $73 \%$ compared with medical treatment alone [239]. Additionally, the study revealed that a combination of lipid-lowering treatments, such as statins, ezetimibe, and nicotinic acid with apheresis, reduced major adverse cardiac events up to $88 \%$ over a 10 -year follow-up period [183, 240]. In a prospective observational multicenter study including 170 participants with Lp(a)-HLP and progressive CVD, comparable results were stated; single apheresis treatment decrease $\mathrm{Lp}(\mathrm{a})$ levels by $68.1 \%$, and therapy over a period of 5 years significantly decreased the yearly CVD occurrence rates [241]. Other important benefits of apheresis include lowering the markers of vascular inflammation and improving blood rheology [242]. In addition to removing Lp(a) mass, lipoprotein apheresis reduces the activities of OxPLs and lipoprotein-associated phospholipase A2, which are bound to $\operatorname{Lp}(\mathrm{a})$ [225]. One of the significant drawbacks of apheresis is the rapid rebound of $\operatorname{Lp}(\mathrm{a})$ levels to those at the baseline within two weeks of intervention, thus requiring repeated, expensive, weekly sessions with limited access to treatment [183].

\section{Conclusion}

Elevated $\mathrm{Lp}(\mathrm{a})$ concentration is dominantly inherited and was first described in the 1960s as a qualitative (Lp+, Lp-) genetic trait [8]. However, we now know that elevated Lp(a) concentration is a quantitative genetic trait influenced mainly by the LPA gene located on chromosome 6 (6q26-27) [23]. This gene is responsible for the inverse relationship between $\operatorname{Lp}(\mathrm{a})$ size, which may vary within and among individuals, and $\mathrm{Lp}(\mathrm{a})$ plasma concentration. This size heterogeneity is a unique phenomenon among lipoproteins, which usually have constant masses. The similarity of the two main parts of $\operatorname{Lp}(\mathrm{a})$ to the LDL and PLG molecules strongly enhances its atherogenicity. OxPLs play a key role in the pathogenesis of $L p(a)$ and may significantly contribute to the atherogenicity of $\mathrm{Lp}(\mathrm{a})$ and its association with increased risk for CVD. Individuals with low $\mathrm{Lp}(\mathrm{a})$ levels do not express any physical or metabolic abnormalities. However, numerous studies have shown that individuals with elevated $\mathrm{Lp}(\mathrm{a})$ concentrations $>300 \mathrm{mg} / \mathrm{L}$ are at increased risk of atherosclerosis, especially if LDL levels are high. Lp(a) measurement and interpretation have many challenges. For instance, the size variation in the apo(a) moiety of $\mathrm{Lp}$ (a) leads to overestimation or underestimation of $\mathrm{Lp}(\mathrm{a})$ concentrations. The development of isoform-independent assays has helped to significantly improve $L p(a)$ measurements. Another important challenge is the contribution of $\mathrm{Lp}$ (a) cholesterol to LDL-C when using the Friedewald formula, which may require a mathematical correction before any interpretation is made [170].

Reducing LDL levels through healthy diet and exercise or even through extensive statin treatment does not significantly influence the reduction in $\mathrm{Lp}(\mathrm{a})$ levels. However, these interventions should be vigorously implemented in the lifestyles of patients with high Lp(a) levels. Indeed, studies have shown that the risk of CVD in patients with high Lp(a) levels is dramatically reduced by lowering LDL-C. There is no approved drug on the market that directly reduces $\mathrm{Lp}(\mathrm{a})$ levels. Many of the multiple-effect lipid-lowering treatments decrease Lp(a) levels without a clear clinical outcome. IONIS ASOs are the only known investigational drugs that block the formation of apo(a) directly and dramatically lower $\mathrm{Lp}(\mathrm{a})$ levels. Extracorporeal elimination with apheresis is the most effective, well-tolerated, and approved treatment for lowering $\mathrm{Lp}$ (a) to date. However, apheresis has significant drawbacks. For instance, the Lp(a) levels rebound every two weeks. Thus, this costly and limited treatment has to be repeated every so often.

\section{Abbreviations}

$\begin{array}{ll}\text { CVD: } & \text { Cardiovascular disease } \\ \text { GBD: } & \text { Global burden disease } \\ \text { IHD: } & \text { Ischemic heart disease } \\ \text { LDL-C: } & \text { Low-density lipoprotein cholesterol } \\ \text { TG: } & \text { Triglyceride } \\ \text { HDL-C: } & \text { High-density lipoprotein-cholesterol } \\ \text { Lp(a): } & \text { Lipoprotein(a) } \\ \text { Apo: } & \text { Apolipoprotein } \\ \text { K: } & \text { Kringle } \\ \text { CAD: } & \text { Coronary artery disease } \\ \text { Apo-B100: } & \text { Apolipoprotein-B100 } \\ \text { CE: } & \text { Cholesteryl esters } \\ \text { Apo(a): } & \text { Apolipoprotein(a) } \\ \text { PLG: } & \text { Plasminogen } \\ \text { tPA: } & \text { Tissue plasminogen activator } \\ \text { uPA: } & \text { Urokinase plasminogen activator } \\ \text { VSMC: } & \text { Vascular smooth muscle cell } \\ \text { LBS: } & \text { Lysine binding sites } \\ \text { ER: } & \text { Endoplasmic reticulum } \\ \text { Cys: } & \text { Cysteine } \\ \text { LDLR: } & \text { LDL receptor } \\ \text { PCSK9: } & \text { Proprotein convertase subtilisin/kexin } \\ & \end{array}$




\begin{tabular}{|c|c|}
\hline & type 9 \\
\hline HepG2: & Human hepatoma cells G2 \\
\hline PlgRKT: & Plasminogen receptor $(\mathrm{KT})$ \\
\hline MMPs: & Matrix metalloproteinases \\
\hline MAPK: & Mitogen-activated protein kinase \\
\hline bFGF: & Basic fibroblast growth factor \\
\hline TGF- $\beta 1:$ & Transforming growth factor- $\beta 1$ \\
\hline TNF- $\alpha:$ & Tumor necrosis factor- $\alpha$ \\
\hline OxPLs: & Oxidized phospholipids \\
\hline Lp-PLA ${ }_{2}:$ & Lipoprotein associated-phospholipase A2 \\
\hline PAI-1: & Plasminogen activator inhibitor-1 \\
\hline u-PA: & Urinary-type plasminogen activators \\
\hline OxLp(a): & Oxidized Lp(a) \\
\hline OxLDL: & Oxidized LDL \\
\hline NADPH: & $\begin{array}{l}\text { Nicotinamide adenine dinucleotide } \\
\text { phosphate }\end{array}$ \\
\hline MPO: & Myeloperoxidase \\
\hline ROS: & Reactive oxygen species \\
\hline LPO: & Lipoxygenase \\
\hline TLR-4: & Toll-like receptors 4 \\
\hline PPR: & Pattern-recognition receptors \\
\hline PAF: & Platelet activating factor \\
\hline VE-cadherin: & Vascular endothelial cadherin \\
\hline VEGFR2: & $\begin{array}{l}\text { Vascular endothelial growth factor } \\
\text { receptor } 2\end{array}$ \\
\hline MLC: & Myosin light chain \\
\hline MLCK: & MLC kinase \\
\hline EP2: & E-type prostaglandin \\
\hline cAMP: & Cyclic AMP \\
\hline PI3K: & Phosphoinositide 3 kinase \\
\hline CS-1: & Connecting segment 1 \\
\hline VCAM-1: & Vascular cell adhesion molecule-1 \\
\hline ICAM-1: & Intercellular adhesion molecule-1 \\
\hline SR-B1: & Scavenger receptor class B type 1 \\
\hline MKP1: & $\begin{array}{l}\text { Mitogen activated protein kinase } \\
\text { phosphatase } 1\end{array}$ \\
\hline CD36: & Cluster determinant 36 \\
\hline EGFR: & Epidermal growth factor receptor \\
\hline MCP-1: & Chemoattractant molecule 1 \\
\hline $\mathrm{Ca}^{+2}:$ & Calcium \\
\hline $\operatorname{PPAR} \alpha:$ & $\begin{array}{l}\text { Peroxisome proliferator-activated } \\
\text { receptor } \alpha\end{array}$ \\
\hline MIP-2: & Macrophage inhibitor protein-2 \\
\hline IL-1 $\beta$ : & IL-1 beta \\
\hline iNOS: & Inducible nitric oxide synthase \\
\hline TNFa: & Tumor necrosis factor-alfa \\
\hline RANTES: & $\begin{array}{l}\text { Regulated upon activation, normal T-cell } \\
\text { expressed, and secreted }\end{array}$ \\
\hline GEFs: & Guanine nucleotide exchange factors \\
\hline IL: & Interleukin \\
\hline MMPs: & Matrix metalloproteinases \\
\hline VSMC: & Vascular smooth muscle \\
\hline NF- $\kappa \mathrm{B}:$ & $\begin{array}{l}\text { Nuclear factor light-chain-enhancer of } \\
\text { activated B }\end{array}$ \\
\hline ERK: & Extracellular signal-regulated kinase () \\
\hline Elk-1: & ETS-like transcription factor 1 \\
\hline Klf4: & Krüppel-like factor 4 \\
\hline HDACs: & Histone deacetylates \\
\hline TGF- $\beta$ : & Transforming growth factor- $\beta$ \\
\hline
\end{tabular}

PDGF-BB: $\quad$ Platelet-derived growth factor

Cx43: Connexin 43

GALT2: Galactosyltransferase-2

LacCer: $\quad$ Lactosylceramide

PCNA: $\quad$ Proliferating cell nuclear antigen

NOX2: $\quad$ NADPH oxidase 2

PARP-1: $\quad$ Adenosine diphosphate-ribose polymerase-1

LKB1: $\quad$ Liver kinase B1

AMPK: $\quad$ Adenosine monophosphate-activated

mTOR: $\quad$ Mammalian target of rapamycin

TF: $\quad$ Tissue factor

TFPI: Tissue factor pathway inhibitor

NFAT: $\quad$ Nuclear factor of activated T cells

PKC: $\quad$ Protein kinase $\mathrm{C}$

EGR-1: $\quad$ Early growth response protein 1

MEK: Metenkephalin

ERK:

IFCC:

Extracellular signal-related kinase 1/2

International Federation of Clinical

Chemistry and Laboratory Medicine

WHO: World Health Organization

HGH: Human growth hormone

IGF-I: Insulin-like growth factor I

ACTH: Adrenocorticotrophic hormone administration

HMG-CoA: 3-Hydroxy-3-methyl-glutaryl-coenzyme

ASO: $\quad$ Antisense oligonucleotide

siRNA: $\quad$ Small interfering RNA molecules

HoFH: Homozygous familial

MTTP: $\quad$ Microsomal triglyceride transfers protein

CETP: Cholesterylester transfer protein.

\section{Conflicts of Interest}

The authors declare that they have no conflicts of interest regarding the publication of this paper.

\section{Acknowledgments}

We would like to express our special thanks of gratitude to Dr. Karin Humphries for her help in editing this manuscript. Finally, the support of the Saudi Arabian Cultural Bureau in Canada and University of Jeddah in Saudi Arabia to Motasim M. Jawi is gratefully acknowledged.

\section{References}

[1] A. C. Finney, K. Y. Stokes, C. B. Pattillo, and A. W. Orr, "Integrin signaling in atherosclerosis," Cellular and Molecular Life Sciences, vol. 74, no. 12, pp. 2263-2282, 2017.

[2] M. Luna-Luna, A. Medina-Urrutia, G. Vargas-Alarcon, F. Coss-Rovirosa, J. Vargas-Barron, and O. Perez-Mendez, "Adipose tissue in metabolic syndrome: onset and progression of atherosclerosis," Archives of Medical Research, vol. 46, no. 5, pp. 392-407, 2015. 
[3] C. Giannini, T. de Giorgis, A. Scarinci et al., "Obese related effects of inflammatory markers and insulin resistance on increased carotid intima media thickness in pre-pubertal children," Atherosclerosis, vol. 197, no. 1, pp. 448-456, 2008.

[4] S. C. Bergheanu, M. C. Bodde, and J. W. Jukema, "Pathophysiology and treatment of atherosclerosis," Netherlands Heart Journal, vol. 25, no. 4, pp. 231-242, 2017.

[5] P. R. Kamstrup, "Lipoprotein (a) and ischemic heart disease-a causal association? A Review," Atherosclerosis, vol. 211, no. 1, pp. 15-23, 2010.

[6] S. Barquera, A. Pedroza-Tobías, C. Medina et al., "Global overview of the epidemiology of atherosclerotic cardiovascular disease," Archives of Medical Research, vol. 46, no. 5, pp. 328338, 2015.

[7] A. Giordano, M. Peruzzi, A. G. Marullo et al., "What we learned with recent network meta-analyses on atherosclerosis prevention and treatment," Current Atherosclerosis Reports, vol. 19, no. 2, p. 8, 2017.

[8] K. Schmidt, A. Noureen, F. Kronenberg, and G. Utermann, "Structure, function, and genetics of lipoprotein (a)," Journal of Lipid Research, vol. 57, no. 8, pp. 1339-1359, 2016.

[9] K. Berg, "A new serum type system in man-the Ld system," Vox Sanguinis, vol. 10, no. 5, pp. 513-527, 1965.

[10] F. Nassir, D. K. Bonen, and N. O. Davidson, "Apolipoprotein (a) synthesis and secretion from hepatoma cells is coupled to triglyceride synthesis and secretion," Journal of Biological Chemistry, vol. 273, no. 28, pp. 17793-17800, 1998.

[11] S. M. Marcovina, M. L. Koschinsky, J. J. Albers, and S. Skarlatos, "Report of the national heart, lung, and blood institute workshop on lipoprotein (a) and cardiovascular disease: recent advances and future directions," Clinical Chemistry, vol. 49, no. 11, pp. 1785-1796, 2003.

[12] J. W. McLean, J. E. Tomlinson, W. J. Kuang et al., "cDNA sequence of human apolipoprotein (a) is homologous to plasminogen," Nature, vol. 330, no. 6144, p. 132, 1987.

[13] L. T. Mackinnon, L. Y. Hubinger, and F. Lepre, "Effects of physical activity and diet on lipoprotein (a)," Medicine and Science in Sports and Exercise, vol. 29, no. 11, pp. 1429-1436, 1997.

[14] P. Libby, "Lipoprotein (a): a frustrating final frontier in lipid management?" JACC: Basic to Translational Science, vol. 1, no. 6, pp. 428-431, 2016.

[15] The Emerging Risk Factors Collaboration, "Lipoprotein(a) concentration and the risk of coronary heart disease, stroke, and nonvascular mortality," The Journal of the American Medical Association, vol. 302, no. 4, pp. 412-423, 2009.

[16] S. R. Holmer, C. Hengstenberg, H. G. Kraft et al., "Association of polymorphisms of the apolipoprotein (a) gene with lipoprotein (a) levels and myocardial infarction," Circulation, vol. 107, no. 5, pp. 696-701, 2003.

[17] S. Tsimikas, "A test in context: lipoprotein (a): diagnosis, prognosis, controversies, and emerging therapies," Journal of the American College of Cardiology, vol. 69, no. 6, pp. 692-711, 2017.

[18] E. Orsó and G. Schmitz, "Lipoprotein (a) and its role in inflammation, atherosclerosis and malignancies," Clinical Research in Cardiology Supplements, vol. 12, no. 1, pp. 31-37, 2017.

[19] S. M. Marcovina and J. J. Albers, "Lipoprotein (a) measurements for clinical application," Journal of Lipid Research, vol. 57, no. 4, pp. 526-537, 2016.
[20] R. Siekmeier, H. Scharnagl, G. M. Kostner, T. Grammer, T. Stojakovic, and W. März, "Lipoprotein (a) - structure, epidemiology, function and diagnostics of a cardiovascular risk marker," The Open Clinical Chemistry Journal, vol. 1, pp. 79-91, 2008.

[21] G. Lippi and G. Guidi, "Lipoprotein (a): from ancestral benefit to modern pathogen?" QJM: An International Journal of Medicine, vol. 93, no. 2, pp. 75-84, 2000.

[22] S. M. Marcovina, J. J. Albers, B. Gabel, M. L. Koschinsky, and V. P. Gaur, "Effect of the number of apolipoprotein (a) kringle 4 domains on immunochemical measurements of lipoprotein (a)," Clinical Chemistry, vol. 41, no. 2, pp. 246-255, 1995.

[23] T. A. Jacobson, "Lipoprotein (a), cardiovascular disease, and contemporary management," Mayo Clinic Proceedings, vol. 88, no. 11, pp. 1294-1311, 2013.

[24] A. von Zychlinski, M. Williams, S. McCormick, and T. Kleffmann, "Absolute quantification of apolipoproteins and associated proteins on human plasma lipoproteins," Journal of Proteomics, vol. 25, no. 106, pp. 181-190, 2014.

[25] A. von Zychlinski, T. Kleffmann, M. J. Williams, and S. P. McCormick, "Proteomics of lipoprotein (a) identifies a protein complement associated with response to wounding," Journal of Proteomics, vol. 74, no. 12, pp. 2881-2891, 2011.

[26] A. L. White, B. Guerra, and R. E. Lanford, "Influence of allelic variation on apolipoprotein (a) folding in the endoplasmic reticulum," Journal of Biological Chemistry, vol. 272, no. 8, pp. 5048-5055, 1997.

[27] M. B. Boffa and M. L. Koschinsky, "Lipoprotein (a): truly a direct prothrombotic factor in cardiovascular disease?" Journal of Lipid Research, vol. 57, no. 5, pp. 745-757, 2016.

[28] A. M. Scanu and C. Edelstein, "Learning about the structure and biology of human lipoprotein [a] through dissection by enzymes of the elastase family: facts and speculations," Journal of Lipid Research, vol. 38, no. 11, pp. 2193-2206, 1997.

[29] A. Cai, L. Li, Y.Zhang, Y. Mo, W. Mai, and Y.Zhou, "Lipoprotein (a): a promising marker for residual cardiovascular risk assessment," Disease Markers, vol. 35, no. 5, pp. 551-559, 2013.

[30] P. Deloukas, S. Kanoni, C. Willenborg et al., "Large-scale association analysis identifies new risk loci for coronary artery disease," Nature Genetics, vol. 45, no. 1, p. 25, 2013.

[31] J. S. Schultz, D. C. Shreffler, C. F. Sing, and N. R. Harvie, “The genetics of the Lp antigen: I. Its quantitation and distribution in a sample population," Annals of Human Genetics, vol. 38, no. 1, pp. 39-46, 1974.

[32] C. Ehnholm, H. Garoff, K. Simons, H. Aro, "Purification and quantitation of the human plasma lipoprotein carrying the Lp (a) antigen," Biochimica et Biophysica Acta (BBA)-Protein Structure, vol. 236, no. 2, pp. 431-439, 1971.

[33] H. H. Hobbs and A. L. White, "Lipoprotein (a): intrigues and insights," Current Opinion in Lipidology, vol. 10, no. 3, pp. 225-236, 1999.

[34] B. Enkhmaa, E. Anuurad, and L. Berglund, "Lipoprotein (a): impact by ethnicity and environmental and medical conditions," Journal of Lipid Research, vol. 57, no. 7, pp. 1111-1125, 2016.

[35] C. Marcoux, S. Lussier-Cacan, J. Davignon, and J. S. Cohn, "Association of Lp (a) rather than integrally-bound apo (a) with triglyceride-rich lipoproteins of human subjects," Biochimica et Biophysica Acta (BBA)-Lipids and Lipid Metabolism, vol. 1346, no. 3, pp. 261-274, 1997. 
[36] K. M. Kostner, W. März, and G. M. Kostner, "When should we measure lipoprotein (a)?" European Heart Journal, vol. 34, no. 42, pp. 3268-3276, 2013.

[37] M. L. Koschinsky and M. B. Boffa, "Lipoprotein (a): an important cardiovascular risk factor and a clinical conundrum," Endocrinology and Metabolism Clinics, vol. 43, no. 4, pp. 949-962, 2014.

[38] A. Beheshtian, S. G. Shitole, A. Z. Segal et al., "Lipoprotein (a) level, apolipoprotein (a) size, and risk of unexplained ischemic stroke in young and middle-aged adults," Atherosclerosis, vol. 1, no. 253, pp. 47-53, 2016.

[39] C. García-Gómez, M. Bianchi, D. de la Fuente et al., "Inflammation, lipid metabolism and cardiovascular risk in rheumatoid arthritis: a qualitative relationship?" World Journal of Orthopedics, vol. 5, no. 3, 304 pages, 2014.

[40] K. Kotani and M. Banach, "Lipoprotein (a) and inhibitors of proprotein convertase subtilisin/kexin type 9," Journal of Thoracic Disease, vol. 9, no. 1, pp. E78-E82, 2017.

[41] S. Frank, S. Durovic, and G. M. Kostner, "Structural requirements of apo-a for the lipoprotein-a assembly," Biochemical Journal, vol. 304, no. 1, pp. 27-30, 1994.

[42] M. Naruszewicz, E. Selinger, R. Dufour, and J. Davignon, "Probucol protects lipoprotein (a) against oxidative modification," Metabolism, vol. 41, no. 11, pp. 1225-1228, 1992.

[43] A. L. White and R. E. Lanford, "Cell surface assembly of lipoprotein (a) in primary cultures of baboon hepatocytes," Journal of Biological Chemistry, vol. 269, no. 46, pp. 2871628723, 1994.

[44] C. Brunner, H. G. Kraft, G. Utermann, and H. J. Müller, "Cys4057 of apolipoprotein (a) is essential for lipoprotein (a) assembly," Proceedings of the National Academy of Sciences, vol. 90, no. 24, pp. 11643-11647, 1993.

[45] J. Hoover-Plow and M. Huang, "Lipoprotein (a) metabolism: potential sites for therapeutic targets," Metabolism, vol. 62, no. 4, pp. 479-491, 2013.

[46] M. R. Diffenderfer, S. Lamon-Fava, S. M. Marcovina et al., "Distinct metabolism of apolipoproteins (a) and B-100 within plasma lipoprotein (a)," Metabolism, vol. 65, no. 4, pp. 381390, 2016.

[47] S. Frank, K. Krasznai, S. Durovic et al., "High-level expression of various apolipoprotein (a) isoforms by "transferrinfection": the role of kringle IV sequences in the extracellular association with low-density lipoprotein," Biochemistry, vol. 33, no. 40, pp. 12329-12339, 1994.

[48] M. E. Frischmann, K. Ikewaki, E. Trenkwalder et al., "In vivo stable-isotope kinetic study suggests intracellular assembly of lipoprotein (a)," Atherosclerosis, vol. 225, no. 2, pp. 322-327, 2012.

[49] A. Gries, J. Nimpf, M. Nimpf, H. Wurm, and G. M. Kostner, "Free and Apo B-associated Lpa-specific protein in human serum," Clinica Chimica Acta, vol. 164, no. 1, pp. 93-100, 1987.

[50] M. Sharma, G. M. Redpath, M. J. Williams, and S. P. McCormick, "Recycling of apolipoprotein (a) after PlgRKT-mediated endocytosis of lipoprotein (a)," Circulation Research, vol. 120, no. 7, pp. 1091-1102, 2017.

[51] C. A. Scipione, M. L. Koschinsky, and M. B. Boffa, "Lipoprotein (a) in clinical practice: new perspectives from basic and translational science," Critical Reviews in Clinical Laboratory Sciences, vol. 55, no. 1, pp. 33-54, 2018.
[52] D. J. Rader, W. Cain, K. Ikewaki et al., "The inverse association of plasma lipoprotein (a) concentrations with apolipoprotein (a) isoform size is not due to differences in Lp (a) catabolism but to differences in production rate," The Journal of Clinical Investigation, vol. 93, no. 6, pp. 2758-2763, 1994.

[53] R. C. Maranhão, P. O. Carvalho, C. C. Strunz, and F. Pileggi, "Lipoprotein (a): structure, pathophysiology and clinical implications," Arquivos Brasileiros de Cardiologia, vol. 103, no. 1, pp. 76-84, 2014.

[54] X. P. Yang, M. J. Amar, B. Vaisman et al., "Scavenger receptorBI is a receptor for lipoprotein (a)," Journal of Lipid Research, vol. 54, no. 9, pp. 2450-2457, 2013.

[55] W. März, A. Beckmann, H. Scharnagl et al., "Heterogeneous lipoprotein (a) size isoforms differ by their interaction with the low density lipoprotein receptor and the low density lipoprotein receptor-related protein $/ \alpha 2$-macroglobulin receptor," FEBS Letters, vol. 325, no. 3, pp. 271-275, 1993.

[56] A. Hrzenjak, S. Frank, W. O. Xingde, Z. H. Yonggang, T. Van Berkel, and G. M. Kostner, "Galactose-specific asialoglycoprotein receptor is involved in lipoprotein (a) catabolism," Biochemical Journal, vol. 376, no. 3, pp. 765-771, 2003.

[57] M. E. Frischmann, F. Kronenberg, E. Trenkwalder et al., "In vivo turnover study demonstrates diminished clearance of lipoprotein (a) in hemodialysis patients," Kidney International, vol. 71, no. 10, pp. 1036-1043, 2007.

[58] F. Kronenberg, "Causes and consequences of lipoprotein (a) abnormalities in kidney disease," Clinical and Experimental Nephrology, vol. 18, no. 2, pp. 234-237, 2014.

[59] B. Kollerits, M. Auinger, V. Reisig et al., "Lipoprotein (a) as a predictor of cardiovascular disease in a prospectively followed cohort of patients with type 1 diabetes," Diabetes Care, vol. 29, no. 7, pp. 1661-1663, 2006.

[60] K. M. Kostner, S. Banyai, M. Banyai et al., "Urinary apolipoprotein (a) excretion in patients with proteinuria," Annals of Medicine, vol. 30, no. 5, pp. 497-502, 1998.

[61] F. Kronenberg, E. Trenkwalder, A. Lingenhel et al., "Renovascular arteriovenous differences in Lp [a] plasma concentrations suggest removal of Lp [a] from the renal circulation," Journal of Lipid Research, vol. 38, no. 9, pp. 1755-1763, 1997.

[62] K. M. Kostner, M. Jansen, G. Maurer, and K. Derfler, "LDLapheresis significantly reduces urinary apo (a) excretion," European Journal of Clinical Investigation., vol. 27, no. 1, pp. 93-95, 1997 Jan.

[63] K. M. Kostner, G. M. Kostner, "Therapy of Hyper-Lp (a)," Atherosclerosis: Diet and Drugs, Springer, Berlin, Heidelberg, pp. 519-536, 2005.

[64] J. S. Kim, J. H. Chang, H. K. Yu et al., "Inhibition of angiogenesis and angiogenesis-dependent tumor growth by the cryptic kringle fragments of human apolipoprotein (a)," Journal of Biological Chemistry, vol. 278, no. 31, pp. 29000-29008, 2003.

[65] V. Schulter, P. Koolwijk, E. Peters et al., "Impact of apolipoprotein (a) on in vitro angiogenesis," Arteriosclerosis, Thrombosis, and Vascular Biology, vol. 21, no. 3, pp. 433-438, 2001.

[66] J. Thillet, C. Doucet, J. Chapman, B. Herbeth, D. Cohen, and L. Faure-Delanef, "Elevated lipoprotein (a) levels and small apo (a) isoforms are compatible with longevity: evidence from a large population of French centenarians," Atherosclerosis, vol. 136, no. 2, pp. 389-394, 1998. 
[67] G. Pepe, V. Di Perna, F. Resta et al., "In search of a biological pattern for human longevity: impact of apo A-IV genetic polymorphisms on lipoproteins and the hyper-Lp (a) in centenarians," Atherosclerosis, vol. 137, no. 2, pp. 407-417, 1998.

[68] O. R. Etingin, D. P. Hajjar, K. A. Hajjar, P. C. Harpel, and R. L. Nachman, "Lipoprotein (a) regulates plasminogen activator inhibitor-1 expression in endothelial cells. A potential mechanism in thrombogenesis," Journal of Biological Chemistry, vol. 266, no. 4, pp. 2459-2465, 1991.

[69] I. Missala, U. Kassner, and E. Steinhagen-Thiessen, "A systematic literature review of the association of lipoprotein (a) and autoimmune diseases and atherosclerosis," International Journal of Rheumatology, vol. 2012, pp. 1-10, 2012.

[70] K. Riches and K. E. Porter, "Lipoprotein (a): cellular effects and molecular mechanisms," Cholesterol, vol. 2012, pp. 1-10, 2012.

[71] G. Lippi, V. Braga, S. Adami, and G. Guidi, "Modification of serum apolipoprotein AI, apolipoprotein B and lipoprotein (a) levels after bisphosphonates-induced acute phase response," Clinica Chimica Acta, vol. 271, no. 1, pp. 79-87, 1998.

[72] R. Ramharack, D. Barkalow, and M. A. Spahr, "Dominant negative effect of TGF- $\beta 1$ and TNF- $\alpha$ on basal and IL-6induced lipoprotein (a) and apolipoprotein (a) mRNA expression in primary monkey hepatocyte cultures," Arteriosclerosis, Thrombosis, and Vascular Biology, vol. 18, no. 6, pp. 984-990, 1998.

[73] M. Pirro, V. Bianconi, F. Paciullo, M. R. Mannarino, F. Bagaglia, and A. Sahebkar, "Lipoprotein (a) and inflammation: a dangerous duet leading to endothelial loss of integrity," Pharmacological Research, vol. 1, no. 119, pp. 178-187, 2017.

[74] S. Tsimikas and J. L. Witztum, "The role of oxidized phospholipids in mediating lipoprotein (a) atherogenicity," Current Opinion in Lipidology, vol. 19, no. 4, pp. 369-377, 2008.

[75] C. Bergmark, A. Dewan, A. Orsoni et al., "A novel function of lipoprotein [a] as a preferential carrier of oxidized phospholipids in human plasma," Journal of Lipid Research, vol. 49, no. 10, pp. 2230-2239, 2008.

[76] C. J. Binder, M. K. Chang, P. X. Shaw et al., "Innate and acquired immunity in atherogenesis," Nature Medicine, vol. 8, no. 11, pp. 1218-1226, 2002.

[77] C. Edelstein, B. Philips, D. Pfaffinger, and A. M. Scanu, "The oxidized phospholipids linked to human apolipoprotein (a) do not derive from circulating low-density lipoproteins and are probably of cellular origin," The FASEB Journal, vol. 23, no. 3, pp. 950-956, 2009.

[78] C. Edelstein, D. Pfaffinger, J. Hinman et al., "Lysinephosphatidylcholine adducts in kringle $\mathrm{V}$ impart unique immunological and potential pro-inflammatory properties to human apolipoprotein (a)," Journal of Biological Chemistry, vol. 278, no. 52, pp. 52841-52847, 2003.

[79] Y. Yano, K. Shimokawa, Y. Okada, and A. Noma, "Immunolocalization of lipoprotein (a) in wounded tissues," Journal of Histochemistry \& Cytochemistry, vol. 45, no. 4, pp. 559-568, 1997.

[80] E. Anglés-Cano, D. A. de la Peña, and S. Loyau, "Inhibition of fibrinolysis by lipoprotein(a)," Annals of the New York Academy Sciences, vol. 936, pp. 261-275, 2001.

[81] J. Loscalzo, M. Weinfeld, G. M. Fless, and A. M. Scanu, "Lipoprotein (a), fibrin binding, and plasminogen activation,"
Arteriosclerosis: An Official Journal of the American Heart Association, Inc, vol. 10, no. 2, pp. 240-245, 1990.

[82] L. B. Nielsen, B. G. Nordestgaard, S. Stender, A. Niendorf, and K. Kjeldsen, "Transfer of lipoprotein (a) and LDL into aortic intima in normal and in cholesterol-fed rabbits," Arteriosclerosis, Thrombosis, and Vascular Biology, vol. 15, no. 9, pp. 1492-1502, 1995.

[83] B. G. Nordestgaard and A. Langsted, "Lipoprotein (a) as a cause of cardiovascular disease: insights from epidemiology, genetics, and biology," Journal of Lipid Research, vol. 57, no. 11, pp. 1953-1975, 2016.

[84] P. Barter, "The inflammation: lipoprotein cycle," Atherosclerosis Supplements, vol. 6, no. 2, pp. 15-20, 2005.

[85] L. B. Nielsen, S. Stender, K. Kjeldsen, and B. G. Nordestgaard, "Specific accumulation of lipoprotein (a) in balloon-injured rabbit aorta in vivo," Circulation Research, vol. 78, no. 4, pp. 615-626, 1996.

[86] L. B. Nielsen, S. Stender, M. Jauhiainen, and B. G. Nordestgaard, "Preferential influx and decreased fractional loss of lipoprotein (a) in atherosclerotic compared with nonlesioned rabbit aorta," The Journal of Clinical Investigation, vol. 98, no. 2, pp. 563-571, 1996.

[87] S. D. Hughes, X. J. Lou, S. Ighani et al., "Lipoprotein (a) vascular accumulation in mice. In vivo analysis of the role of lysine binding sites using recombinant adenovirus," The Journal of Clinical Investigation, vol. 100, no. 6, pp. 1493-1500, 1997.

[88] N. W. Boonmark, X. J. Lou, Z. J. Yang et al., "Modification of apolipoprotein (a) lysine binding site reduces atherosclerosis in transgenic mice," The Journal of Clinical Investigation, vol. 100, no. 3, pp. 558-564, 1997.

[89] A. A. Higazi, E. Lavi, K. Bdeir et al., "Defensin stimulates the binding of lipoprotein (a) to human vascular endothelial and smooth muscle cells," Blood, vol. 89, no. 12, pp. 4290-4298, 1997.

[90] L. Huang, K. L. Chambliss, X. Gao et al., "SR-B1 drives endothelial cell LDL transcytosis via DOCK4 to promote atherosclerosis," Nature, vol. 569, no. 7757, p. 7565, 2019.

[91] F. M. van der Valk, S. Bekkering, J. Kroon et al., "Oxidized phospholipids on lipoprotein (a) elicit arterial wall inflammation and an inflammatory monocyte response in humans," Circulation, vol. 134, no. 8, pp. 611-624, 2016.

[92] S. Tsimikas, "In vivo markers of oxidative stress and therapeutic interventions," The American Journal of Cardiology, vol. 101, no. 10, pp. S34-S42, 2008.

[93] M. Malaguarnera, M. Vacante, C. Russo et al., "Lipoprotein (a) in cardiovascular diseases," BioMed Research International, vol. 2013, pp. 1-9, 2013.

[94] A. I. Papathanasiou, E. S. Lourida, L. D. Tsironis, J. A. Goudevenos, and A.D. Tselepis, "Short-and long-term elevation of autoantibody titers against oxidized LDL in patients with acute coronary syndromes: role of the lipoprotein-associated phospholipase A2 and the effect of atorvastatin treatment," Atherosclerosis, vol. 196, no. 1, pp. 289-297, 2008.

[95] A. Deb and N. M. Caplice, "Lipoprotein (a): new insights into mechanisms of atherogenesis and thrombosis," Clinical Cardiology, vol. 27, no. 5, pp. 258-264, 2004.

[96] N. Leitinger, "Oxidized phospholipids as modulators of inflammation in atherosclerosis," Current Opinion in Lipidology, vol. 14, no. 5, pp. 421-430, 2003. 
[97] T. Shimizu, "Inflammation-inducing factors of Mycoplasma pneumoniae," Frontiers in Microbiology, vol. 31, no. 7, p. 414, 2016.

[98] I. Botos, D. M. Segal, and D. R. Davies, "The structural biology of Toll-like receptors," Structure, vol. 19, no. 4, pp. 447-459, 2011.

[99] S. Lee, K. G. Birukov, C. E. Romanoski, J. R. Springstead, A. J. Lusis, and J. A. Berliner, "Role of phospholipid oxidation products in atherosclerosis," Circulation Research, vol. 111, no. 6, pp. 778-799, 2012.

[100] S. Tsimikas, "Oxidative biomarkers in the diagnosis and prognosis of cardiovascular disease," The American Journal of Cardiology, vol. 98, no. 11, pp. S9-S17, 2006.

[101] V. Starosta, T. Wu, A. Zimman et al., "Differential regulation of endothelial cell permeability by high and low doses of oxidized 1-palmitoyl-2-arachidonyl-sn-glycero-3-phosphocholine," American Journal of Respiratory Cell and Molecular Biology, vol. 46, no. 3, pp. 331-341, 2012.

[102] M. Pellegrino, E. Furmaniak-Kazmierczak, J. C. LeBlanc et al., "The apolipoprotein (a) component of lipoprotein (a) stimulates actin stress fiber formation and loss of cell-cell contact in cultured endothelial cells," Journal of Biological Chemistry, vol. 279, no. 8, pp. 6526-6533, 2004.

[103] T. Cho, Y. Jung, and M. L. Koschinsky, "Apolipoprotein (a), through its strong lysine-binding site in KIV10, mediates increased endothelial cell contraction and permeability via a Rho/Rho kinase/MYPT1-dependent pathway," Journal of Biological Chemistry, vol. 283, no. 45, pp. 30503-30512, 2008.

[104] O. Dubrovskyi, T. Wu, V. Starosta et al., "A role For VEGFR2 activation in endothelial responses caused by barrier disruptive OXPAPC Concentrations," in A57 pulmonary barriers to edema formation 2012, American Thoracic Society, pp. A1865A1865, 2012.

[105] L. DeMaio, M. Rouhanizadeh, S. Reddy, A. Sevanian, J. Hwang, and T. K. Hsiai, "Oxidized phospholipids mediate occludin expression and phosphorylation in vascular endothelial cells," American Journal of Physiology-Heart and Circulatory Physiology, vol. 290, no. 2, pp. H674-H683, 2006.

[106] R. Li, K. P. Mouillesseaux, D. Montoya et al., "Identification of prostaglandin $\mathrm{E} 2$ receptor subtype 2 as a receptor activated by OxPAPC," Circulation Research, vol. 98, no. 5, pp. 642-650, 2006.

[107] A. L. Cole, G. Subbanagounder, S. Mukhopadhyay, J. A. Berliner, and D. K. Vora, "Oxidized phospholipid-induced endothelial cell/monocyte interaction is mediated by a cAMP-dependent R-Ras/PI3-kinase pathway," Arteriosclerosis, Thrombosis, and Vascular Biology, vol. 23, no. 8, pp. 1384-1390, 2003.

[108] K. D. O'brien, M. D. Allen, T. O. Mcdonald et al., "Vascular cell adhesion molecule-1 is expressed in human coronary atherosclerotic plaques. Implications for the mode of progression of advanced coronary atherosclerosis," The Journal of Clinical Investigation, vol. 92, no. 2, pp. 945-951, 1993.

[109] S. Allen, S. Khan, S. P. Tam, M. Koschinsky, P. Taylor, and M. Yacoub, "Expression of adhesion molecules by Lp (a): a potential novel mechanism for its atherogenicity," The FASEB Journal, vol. 12, no. 15, pp. 1765-1776, 1998.

[110] S.-P. Zhao and D.-Y. Xu, "Oxidized lipoprotein (a) enhanced the expression of P-selectin in cultured human umbilical vein endothelial cells," Thrombosis Research, vol. 100, no. 6, pp. 501-510, 2000.

[111] S. Takami, S. Yamashita, S. Kihara et al., "Lipoprotein (a) enhances the expression of intercellular adhesion molecule- 1 in cultured human umbilical vein endothelial cells," Circulation, vol. 97, no. 8, pp. 721-728, 1998.

[112] P. Libby, "Inflammation in atherosclerosis," Nature, vol. 420, no. 6917, pp. 868-874, 2002.

[113] S. Imaizumi, V. Grijalva, S. Priceman et al., "Mitogenactivated protein kinase phosphatase- 1 deficiency decreases atherosclerosis in apolipoprotein $\mathrm{E}$ null mice by reducing monocyte chemoattractant protein-1 levels," Molecular Genetics and Metabolism, vol. 101, no. 1, pp. 66-75, 2010.

[114] S. Lee, J. R. Springstead, B. W. Parks et al., "Metalloproteinase processing of HBEGF is a proximal event in the response of human aortic endothelial cells to oxidized phospholipids," Arteriosclerosis, Thrombosis, and Vascular Biology, vol. 32, no. 5, pp. 1246-1254, 2012.

[115] N. K. Singh, D. Wang, V. Kundumani-Sridharan, D. Van Quyen, J. Niu, and G. N. Rao, "15-Lipoxygenase-1-enhanced Src-Janus kinase 2-signal transducer and activator of transcription 3 stimulation and monocyte chemoattractant protein-1 expression require redox-sensitive activation of epidermal growth factor receptor in vascular wall remodeling," Journal of Biological Chemistry, vol. 286, no. 25, pp. 22478-22488, 2011.

[116] P. Delerive, C. Furman, E. Teissier, J. C. Fruchart, P. Duriez, and B. Staels, "Oxidized phospholipids activate PPARa in a phospholipase A2-dependent manner," FEBS Letters, vol. 471, no. 1, pp. 34-38, 2000.

[117] H. Lee, W. Shi, P. Tontonoz et al., "Role for peroxisome proliferator-activated receptor $\alpha$ in oxidized phospholipidinduced synthesis of monocyte chemotactic protein-1 and interleukin- 8 by endothelial cells," Circulation Research, vol. 87 , no. 6 , pp. 516-521, 2000.

[118] G. Subbanagounder, J.W. Wong, H. Lee et al., "Epoxyisoprostane and epoxycyclopentenone phospholipids regulate monocyte chemotactic protein- 1 and interleukin- 8 synthesis. Formation of these oxidized phospholipids in response to interleukin1beta," The Journal of Biological Chemistry, vol. 277, no. 9, pp. 7271-7281, 2002.

[119] T. Syrovets, J. Thillet, M. J. Chapman, and T. Simmet, "Lipoprotein (a) is a potent chemoattractant for human peripheral monocytes," Blood, vol. 90, no. 5, pp. 2027-2036, 1997.

[120] P. Wiesner, M. Tafelmeier, D. Chittka et al., "MCP-1 binds to oxidized LDL and is carried by lipoprotein (a) in human plasma," Journal of Lipid Research, vol. 54, no. 7, pp. 1877$1883,2013$.

[121] S. N. Sotiriou, V. V. Orlova, N. Al-Fakhri et al., "Lipoprotein (a) in atherosclerotic plaques recruits inflammatory cells through interaction with Mac-1 integrin," The FASEB Journal, vol. 20, no. 3, pp. 559-561, 2006.

[122] A. Kadl, A. K. Meher, P. R. Sharma et al., "Identification of a novel macrophage phenotype that develops in response to atherogenic phospholipids via Nrf2," Circulation Research, vol. 107, no. 6, pp. 737-746, 2010.

[123] S. Blüml, G. Zupkovitz, S. Kirchberger et al., "Epigenetic regulation of dendritic cell differentiation and function by oxidized phospholipids," Blood, vol. 114, no. 27, pp. 54815489, 2009.

[124] D. Lakshminarayan, T. K. Elajami, S. Devabhaktuni, and F. K. Welty, "Ischemic stroke in a young adult with extremely elevated lipoprotein (a): a case report and review of literature," Journal of Clinical Lipidology, vol. 10, no. 5, pp. 1266-1271, 2016. 
[125] S. O. Rahaman, G. Zhou, and R. L. Silverstein, "Vav protein guanine nucleotide exchange factor regulates CD36 proteinmediated macrophage foam cell formation via calcium and dynamin-dependent processes," Journal of Biological Chemistry, vol. 286, no. 41, pp. 36011-36019, 2011.

[126] M. R. Alexander and G. K. Owens, "Epigenetic control of smooth muscle cell differentiation and phenotypic switching in vascular development and disease," Annual Review of Physiology, vol. 17, no. 74, pp. 13-40, 2012.

[127] M. R. Alexander, M. Murgai, C. W. Moehle, and G. K. Owens, "Interleukin- $1 \beta$ modulates smooth muscle cell phenotype to a distinct inflammatory state relative to PDGF-DD via NFкB-dependent mechanisms," Physiological Genomics, vol. 44, no. 7, pp. 417-429, 2012.

[128] M. R. Bennett, S. Sinha, and G. K. Owens, "Vascular smooth muscle cells in atherosclerosis," Circulation Research, vol. 118, no. 4, pp. 692-702, 2016.

[129] E. Falk, "Pathogenesis of atherosclerosis," Journal of the American College of Cardiology, vol. 47, no. 8, pp. C7-C12, 2006.

[130] T. Ichikawa, H. Unoki, H. Sun et al., "Lipoprotein (a) promotes smooth muscle cell proliferation and dedifferentiation in atherosclerotic lesions of human apo (a) transgenic rabbits," The American Journal of Pathology, vol. 160, no. 1, pp. 227-236, 2002.

[131] N. Komai, R. Morishita, S. Yamada et al., "Mitogenic activity of oxidized lipoprotein (a) on human vascular smooth muscle cells," Hypertension, vol. 40, no. 3, pp. 310-314, 2002.

[132] T. Yoshida, Q. Gan, and G. K. Owens, "Kruppel-like factor 4, Elk-1, and histone deacetylases cooperatively suppress smooth muscle cell differentiation markers in response to oxidized phospholipids," American Journal of Physiology-Cell Physiology, vol. 295, no. 5, pp. C1175-C1182, 2008.

[133] L. S. Shankman, D. Gomez, O. A. Cherepanova et al., "KLF4dependent phenotypic modulation of smooth muscle cells has a key role in atherosclerotic plaque pathogenesis," Nature Medicine, vol. 21, no. 6, pp. 628-637, 2015.

[134] N. A. Pidkovka, O. A. Cherepanova, T. Yoshida et al., "Oxidized phospholipids induce phenotypic switching of vascular smooth muscle cells in vivo and in vitro," Circulation Research, vol. 101, no. 8, pp. 792-801, 2007.

[135] R. M. Lawn, A. D. Pearle, L. L. Kunz et al., "Feedback mechanism of focal vascular lesion formation in transgenic apolipoprotein (a) mice," Journal of Biological Chemistry, vol. 271, no. 49, pp. 31367-31371, 1996.

[136] S. P. Zhao and D. Y. Xu, "Oxidized lipoprotein (a) increases the expression of platelet-derived growth factor-B in human umbilical vein endothelial cells," Clinica Chimica Acta, vol. 296, no. 1-2, pp. 121-133, 2000.

[137] S. R. Johnstone, J. Ross, M. J. Rizzo et al., "Oxidized phospholipid species promote in vivo differential cx43 phosphorylation and vascular smooth muscle cell proliferation," The American Journal of Pathology, vol. 175, no. 2, pp. 916-924, 2009.

[138] S. Kojima, P. C. Harpel, and D. B. Rifkin, "Lipoprotein (a) inhibits the generation of transforming growth factor beta: an endogenous inhibitor of smooth muscle cell migration," The Journal of Cell Biology, vol. 113, no. 6, pp. 1439-1445, 1991.

[139] O. A. Cherepanova, N. A. Pidkovka, O. F. Sarmento et al., "Oxidized phospholipids induce type VIII collagen expression and vascular smooth muscle cell migration," Circulation Research, vol. 104, no. 5, pp. 609-618, 2009.
[140] T. A. Seimon, M. J. Nadolski, X. Liao et al., "Atherogenic lipids and lipoproteins trigger CD36-TLR2-dependent apoptosis in macrophages undergoing endoplasmic reticulum stress," Cell Metabolism, vol. 12, no. 5, pp. 467-482, 2010.

[141] K. Heermeier, R. Schneider, A. Heinloth, C. Wanner, S. Dimmeler, and J. Galle, "Oxidative stress mediates apoptosis induced by oxidized low-density lipoprotein and oxidized lipoprotein (a)," Kidney International, vol. 56, no. 4, pp. 1310 1312, 1999.

[142] R. Chen, L. Yang, and T. M. McIntyre, "Cytotoxic phospholipid oxidation products cell death from mitochondrial damage and the intrinsic caspase cascade," Journal of Biological Chemistry, vol. 282, no. 34, pp. 24842-24850, 2007.

[143] A. Loidl, E. Sevcsik, G. Riesenhuber, H. P. Deigner, and A. Hermetter, "Oxidized phospholipids in minimally modified low density lipoprotein induce apoptotic signaling via activation of acid sphingomyelinase in arterial smooth muscle cells," Journal of Biological Chemistry, vol. 278, no. 35, pp. 32921-32928, 2003.

[144] G. H. Li, X. L. Lin, H. Zhang et al., "Ox-Lp (a) transiently induces HUVEC autophagy via an ROS-dependent PAPR-1LKB1-AMPK-mTOR pathway," Atherosclerosis, vol. 243, no. 1, pp. 223-235, 2015.

[145] L. Hervio, V. Durlach, A. Girard-Globa, and E. AnglesCano, "Multiple binding with identical linkage: a mechanism that explains the effect of lipoprotein (a) on fibrinolysis," Biochemistry, vol. 34, no. 41, pp. 13353-13358, 1995.

[146] L. A. Miles, G. M. Fless, E. G. Levin, A. M. Scanu, and E. F. Plow, "A potential basis for the thrombotic risks associated with lipoprotein (a)," Nature, vol. 339, no. 6222, pp. 301-303, 1989.

[147] E. von Hodenberg, J. Kreuzer, M. Hautmann, T. Nordt, W. Kübler, and C. Bode, "Effects of lipoprotein (a) on success rate of thrombolytic therapy in acute myocardial infarction," The American Journal of Cardiology, vol. 67, no. 16, pp. 1349-1353, 1991.

[148] G. Davì and C. Patrono, "Platelet activation and atherothrombosis," New England Journal of Medicine, vol. 357, no. 24, pp. 2482-2494, 2007.

[149] M. L. Rand, W. Sangrar, M. A. Hancock et al., "Apolipoprotein (a) enhances platelet responses to the thrombin receptoractivating peptide SFLLRN," Arteriosclerosis, Thrombosis, and Vascular Biology, vol. 18, no. 9, pp. 1393-1399, 1998.

[150] L. D. Tsironis, J. V. Mitsios, H. J. Milionis, M. Elisaf, and A. D. Tselepis, "Effect of lipoprotein (a) on platelet activation induced by platelet-activating factor: role of apolipoprotein (a) and endogenous PAF-acetylhydrolase," Cardiovascular Research, vol. 63, no. 1, pp. 130-138, 2004.

[151] K. Chen, W. Li, J. Major, S. O. Rahaman, M. Febbraio, and R. L. Silverstein, "Vav guanine nucleotide exchange factors link hyperlipidemia and a prothrombotic state," Blood, vol. 117, no. 21, pp. 5744-5750, 2011.

[152] J. M. Edelberg, M. Gonzalez-Gronow, and S. V. Pizzo, "Lipoprotein (a) inhibition of plasminogen activation by tissue-type plasminogen activator," Thrombosis Research, vol. 57, no. 1, pp. 155-162, 1990.

[153] N. T. Feric, M. B. Boffa, S. M. Johnston, and M. L. Koschinsky, "Apolipoprotein (a) inhibits the conversion of Glu-plasminogen to Lys-plasminogen: a novel mechanism for lipoprotein (a)mediated inhibition of plasminogen activation," Journal of Thrombosis and Haemostasis, vol. 6, no. 12, pp. 2113-2120, 2008. 
[154] X. F. Cheng, O. Bäck, T. K. Nilsson, E. N. Lundqvist, G. Pohl, and P. Wallén, "Binding of tissue plasminogen activator to human endothelial cells. Importance of the B-chain as a ligand," Biochemical Journal, vol. 287, no. 2, pp. 407-413, 1992.

[155] S. Ren, S. Shatadal, and G. X. Shen, "Protein kinase C- $\beta$ mediates lipoprotein-induced generation of PAI-1 from vascular endothelial cells," American Journal of Physiology-Endocrinology and Metabolism, vol. 278, no. 4, pp. E656-E662, 2000.

[156] L. Hervio, M. J. Chapman, J. Thillet, S. Loyau, and E. AnglesCano, "Does apolipoprotein (a) heterogeneity influence lipoprotein (a) effects on fibrinolysis?” Blood, vol. 82, no. 2, pp. 392-397, 1993.

[157] N. Mackman, "The role of tissue factor and factor VIIa in hemostasis," Anesthesia and Analgesia, vol. 108, no. 5, pp. 1447-1452, 2009.

[158] T. A. Drake, J. H. Morrissey, and T. S. Edgington, "Selective cellular expression of tissue factor in human tissues. Implications for disorders of hemostasis and thrombosis," The American Journal of Pathology, vol. 134, no. 5, p. 1087, 1989.

[159] N. M. Caplice, C. Panetta, T. E. Peterson et al., "Lipoprotein (a) binds and inactivates tissue factor pathway inhibitor: a novel link between lipoproteins and thrombosis," Blood, vol. 98, no. 10, pp. 2980-2987, 2001.

[160] V. N. Bochkov, D. Mechtcheriakova, M. Lucerna et al., "Oxidized phospholipids stimulate tissue factor expression in human endothelial cells via activation of ERK/EGR-1 and Ca++/NFAT," Blood, vol. 99, no. 1, pp. 199-206, 2002.

[161] G. J. Broze, L. A. Warren, W. F. Novotny, D. A. Higuchi, J. J. Girard, and J. P. Miletich, "The lipoprotein-associated coagulation inhibitor that inhibits the factor VII-tissue factor complex also inhibits factor Xa: insight into its possible mechanism of action," Blood, vol. 71, no. 2, pp. 335-343, 1988.

[162] K. M. Kostner and G. M. Kostner, "Factors affecting plasma lipoprotein (a) levels: role of hormones and other nongenetic factors," Seminars in Vascular Medicine, vol. 4, no. 2, pp. 211$214,2004$.

[163] H. Dieplinger, C. Lackner, F. Kronenberg et al., "Elevated plasma concentrations of lipoprotein (a) in patients with endstage renal disease are not related to the size polymorphism of apolipoprotein (a)," The Journal of Clinical Investigation, vol. 91, no. 2, pp. 397-401, 1993.

[164] T. Soulat, S. Loyau, V. Baudouin et al., "Effect of individual plasma lipoprotein (a) variations in vivo on its competition with plasminogen for fibrin and cell binding: an in vitro study using plasma from children with idiopathic nephrotic syndrome," Arteriosclerosis, Thrombosis, and Vascular Biology, vol. 20, no. 2, pp. 575-584, 2000.

[165] E. A. Enas, V. Chacko, A. Senthilkumar, N. Puthumana, and V. Mohan, "Elevated lipoprotein (a) - a genetic risk factor for premature vascular disease in people with and without standard risk factors: a review," Disease-a-Month, vol. 1, no. 52, p. 5, 2006.

[166] D. Yin, P. Shao, and Y. Liu, "Elevated lipoprotein (a) levels predict deep vein thrombosis in acute ischemic stroke patients," Neuroreport, vol. 27, no. 1, pp. 39-44, 2016.

[167] C. Catena, M. Novello, L. Dotto, S. De Marchi, and L. A. Sechi, "Serum lipoprotein (a) concentrations and alcohol consumption in hypertension: possible relevance for cardiovascular damage," Journal of Hypertension, vol. 21, no. 2, pp. 281-288, 2003.

[168] R. Siekmeier, W. März, H. Kronenberger, U. B. Seiffert, and W. Gross, "Effects of cigarette smoking on plasma lipids, apolipoproteins, and lipoprotein (a) in healthy subjects," Clinical Chemistry, vol. 40, no. 7, pp. 1350-1351, 1994.

[169] I. Os, A. Høieggen, A. Larsen et al., "Smoking and relation to other risk factors in postmenopausal women with coronary artery disease, with particular reference to whole blood viscosity and $\beta$-cell function," Journal of Internal Medicine, vol. 253, no. 2, pp. 232-239, 2003.

[170] P. M. da Silva, J. S. Duarte, P. von Hafe, V. Gil, J. N. de Oliveira, and G. de Sousa, "Standardization of laboratory and lipid profile evaluation: a call for action with a special focus in 2016 ESC/EAS dyslipidaemia guidelines-Full report," Atherosclerosis Supplements, vol. 30, no. 31, pp. e1-e12, 2018.

[171] M. R. Hammerman and S. B. Miller, "Effects of growth hormone and insulin-like growth factor I on renal growth and function," The Journal of Pediatrics, vol. 131, no. 1, pp. S17S19, 1997.

[172] M. Clodi, R. Oberbauer, W. Waldhäusl, G. Maurer, G. M. Kostner, and K. Kostner, "Urinary excretion of apo (a) fragments in NIDDM patients," Diabetologia, vol. 40, no. 12, pp. 1455-1460, 1997.

[173] G. M. Kostner, "Lipoprotein (a): metabolismus und beeinflussung des plasmaspiegels," Journal für KardiologieAustrian Journal of Cardiology, vol. 9, no. 7, pp. 321-324, 2002.

[174] G. Gaeta, S. Lanero, S. Barra et al., "Sex hormones and lipoprotein (a) concentration," Expert Opinion on Investigational Drugs, vol. 20, no. 2, pp. 221-238, 2011.

[175] M. S. Hislop, A. S. Gibson, M. I. Lambert, T. D. Noakes, and A. D. Marais, "Effects of androgen manipulation on postprandial triglyceridaemia, low-density lipoprotein particle size and lipoprotein (a) in men," Atherosclerosis, vol. 159, no. 2, pp. 425-432, 2001.

[176] R. Zechner, G. Desoye, M. O. Schweditsch, K. P. Pfeiffer, and G. M. Kostner, "Fluctuations of plasma liproprotein-a concentrations during pregnancy and post partum," Metabolism, vol. 35, no. 4, pp. 333-336, 1986.

[177] E. N. Pearce, "Hypothyroidism and dyslipidemia: modern concepts and approaches," Current Cardiology Reports, vol. 6, no. 6, pp. 451-456, 2004.

[178] M. Paassilta, K. Kervinen, M. Linnaluoto, and Y. A. Kesäniemi, "Alcohol withdrawal-induced change in lipoprotein (a) association with the growth hormone/insulin-like growth factor-I (IGF-I)/IGF-binding protein-1 (IGFBP-1) axis," Arteriosclerosis, Thrombosis, and Vascular Biology, vol. 18, no. 4, pp. 650-654, 1998.

[179] A. Dionyssiou-Asteriou and M. Katimertzi, "Endogenous testosterone and serum apolipoprotein (a) levels," Atherosclerosis, vol. 100, no. 1, pp. 123-126, 1993.

[180] R. Saeedi, M. Li, and J. Frohlich, "Lipoprotein (a): why is it important?" British Columbia Medical Journal, vol. 1, no. 56, pp. 180-182, 2014.

[181] Y. Hirowatari, D. Manita, K. Kamachi, and A. Tanaka, "Effect of dietary modification by calorie restriction on cholesterol levels in lipoprotein (a) and other lipoprotein classes," Annals of Clinical Biochemistry, vol. 54, no. 5, pp. 567-576, 2017.

[182] R.S. Najjar, C. E. Moore, and B. D. Montgomery, "Consumption of a defined, plant-based diet reduces lipoprotein (a), inflammation, and other atherogenic lipoproteins and particles within 4 weeks," Clinical Cardiology, vol. 41, no. 8, pp. 1062-1068, 2018.

[183] E. Kelly and L. Hemphill, "Lipoprotein (a): a lipoprotein whose time has come," Current Treatment Options in Cardiovascular Medicine, vol. 19, no. 7, p. 48, 2017. 
[184] F. Dati, J. R. Tate, S. M. Marcovina, and A. Steinmetz, "First WHO/IFCC international reference reagent for lipoprotein (a) for immunoassay-Lp (a) SRM 2B," Clinical Chemistry and Laboratory Medicine (CCLM), vol. 42, no. 6, pp. 670-676, 2004.

[185] J. P. McConnell, P. A. Guadagno, T. D. Dayspring et al., "Lipoprotein (a) mass: a massively misunderstood metric," Journal of Clinical Lipidology, vol. 8, no. 6, pp. 550-553, 2014.

[186] B. Gencer, F. Kronenberg, E. S. Stroes, and F. Mach, "Lipoprotein (a): the revenant," European Heart Journal, vol. 38, no. 20, pp. 1553-1560, 2017.

[187] A. M. Scanu, "The role of lipoprotein (a) in the pathogenesis of atherosclerotic cardiovascular disease and its utility as predictor of coronary heart disease events," Current Cardiology Reports, vol. 3, no. 5, pp. 385-390, 2001.

[188] C. Labeur, G. Michiels, J. Bury, D. C. Usher, and M. Rosseneu, "Lipoprotein (a) quantified by an enzyme-linked immunosorbent assay with monoclonal antibodies," Clinical Chemistry, vol. 35, no. 7, pp. 1380-1384, 1989.

[189] S. Tsimikas and J. L. Hall, "Lipoprotein (a) as a potential causal genetic risk factor of cardiovascular disease: a rationale for increased efforts to understand its pathophysiology and develop targeted therapies," Journal of the American College of Cardiology, vol. 60, no. 8, pp. 716-721, 2012.

[190] M. Bucci, C. Tana, M. A. Giamberardino, and F. Cipollone, "Lp (a) and cardiovascular risk: investigating the hidden side of the moon," Nutrition, Metabolism and Cardiovascular Diseases, vol. 26, no. 11, pp. 980-986, 2016.

[191] N. Nago, K. Kayaba, J. Hiraoka et al., "Lipoprotein (a) levels in the Japanese population: influence of age and sex, and relation to atherosclerotic risk factors: the Jichi Medical School Cohort Study," American Journal of Epidemiology, vol. 141, no. 9, pp. 815-821, 1995.

[192] A. O. Akanji, A. N. Al-Isa, and L. Thalib, "Determinants of blood levels of some thrombogenic biomarkers in healthy Arab adolescent subjects," Clinical Chemistry and Laboratory Medicine, vol. 49, no. 10, pp. 1681-1690, 2011.

[193] J. Frohlich, M. Dobiášová, L. Adler, and M. Francis, "Gender differences in plasma levels of lipoprotein (a) in patients with angiographically proven coronary artery," Physiological Research, vol. 53, pp. 481-486, 2004.

[194] B. G. Nordestgaard, M. J. Chapman, K. Ray et al., "Lipoprotein (a) as a cardiovascular risk factor: current status," European Heart Journal, vol. 31, no. 23, pp. 2844-2853, 2010.

[195] K. L. Ellis and G. F. Watts, "Is lipoprotein (a) ready for primetime use in the clinic?" Cardiology Clinics, vol. 36, no. 2, pp. 287-298, 2018.

[196] B. G. Nordestgaard, "A test in context: lipid profile, fasting versus nonfasting," Journal of the American College of Cardiology, vol. 70, no. 13, pp. 1637-1646, 2017.

[197] A. L. Catapano, I. Graham, G. De Backer et al., "2016 ESC/EAS guidelines for the management of dyslipidaemias: the task force for the management of dyslipidaemias of the European Society of Cardiology (ESC) and European Atherosclerosis Society (EAS) developed with the special contribution of the European Association for Cardiovascular Prevention \& Rehabilitation (EACPR)," Atherosclerosis, vol. 1, no. 253, pp. 281-344, 2016.

[198] T. J. Anderson, J. Grégoire, R. A. Hegele et al., “2012 update of the Canadian Cardiovascular Society guidelines for the diagnosis and treatment of dyslipidemia for the prevention of cardiovascular disease in the adult," Canadian Journal of Cardiology, vol. 29, no. 2, pp. 151-167, 2013.

[199] A. H. Lichtenstein, L. M. Ausman, W. Carrasco et al., "Effects of canola, corn, and olive oils on fasting and postprandial plasma lipoproteins in humans as part of a National Cholesterol Education Program Step 2 diet," Arteriosclerosis and Thrombosis: a Journal of Vascular Biology, vol. 13, no. 10, pp. 1533-1542, 1993.

[200] G. Luc, J. M. Bard, D. Arveiler et al., "Lipoprotein (a) as a predictor of coronary heart disease: the PRIME Study," Atherosclerosis, vol. 163, no. 2, pp. 377-384, 2002.

[201] V. M. Maher, B. G. Brown, S. M. Marcovina, L. A. Hillger, X. Q. Zhao, and J. J. Albers, "Effects of lowering elevated LDL cholesterol on the cardiovascular risk of lipoprotein (a)," JAMA, vol. 274, no. 22, pp. 1771-1774, 1995.

[202] G. Lippi and G. Targher, "Optimal therapy for reduction of lipoprotein (a)," Journal of Clinical Pharmacy and Therapeutics, vol. 37, no. 1, pp. 1-3, 2012.

[203] C. Yeang, M. Y. Hung, Y. S. Byun et al., "Effect of therapeutic interventions on oxidized phospholipids on apolipoprotein B100 and lipoprotein (a)," Journal of Clinical Lipidology, vol. 10, no. 3, pp. 594-603, 2016.

[204] C. Yeang, J. L. Witztum, and S. Tsimikas, “'LDL-C'= LDL-C+ Lp (a)-C: implications of achieved ultra-low LDL-C levels in the proprotein convertase subtilisin/kexin type 9 era of potent LDL-C lowering," Current Opinion in Lipidology, vol. 26, no. 3, pp. 169-178, 2015.

[205] N. J. Woudberg, S. Pedretti, S. Lecour et al., "Pharmacological intervention to modulate HDL: what do we target?" Frontiers in Pharmacology, vol. 22, no. 8, p. 989, 2018.

[206] A. Sahebkar, Ž. Reiner, L. E. Simental-Mendía, G. Ferretti, and A. F. Cicero, "Effect of extended-release niacin on plasma lipoprotein (a) levels: a systematic review and meta-analysis of randomized placebo-controlled trials," Metabolism, vol. 65, no. 11, pp. 1664-1678, 2016.

[207] M. Akaike, H. Azuma, A. Kagawa et al., "Effect of aspirin treatment on serum concentrations of lipoprotein (a) in patients with atherosclerotic diseases," Clinical Chemistry, vol. 48, no. 9, pp. 1454-1459, 2002.

[208] N. J. Viney, J. C. Van Capelleveen, R. S. Geary et al., "Antisense oligonucleotides targeting apolipoprotein (a) in people with raised lipoprotein (a): two randomised, double-blind, placebocontrolled, dose-ranging trials," The Lancet, vol. 388, no. 10057, pp. 2239-2253, 2016.

[209] S. Tsimikas, N. J. Viney, S. G. Hughes et al., "Antisense therapy targeting apolipoprotein (a): a randomised, doubleblind, placebo-controlled phase 1 study," The Lancet, vol. 386, no. 10002, pp. 1472-1483, 2015.

[210] M. J. Borrelli, A. Youssef, M. B. Boffa, and M. L. Koschinsky, "New frontiers in Lp (a)-targeted therapies," Trends in Pharmacological Sciences, vol. 40, no. 3, pp. 212-225, 2019.

[211] R. D. Santos, F. J. Raal, A. L. Catapano, J. L. Witztum, E. Steinhagen-Thiessen, and S. Tsimikas, "Mipomersen, an antisense oligonucleotide to apolipoprotein B-100, reduces lipoprotein (a) in various populations with hypercholesterolemia: results of 4 phase III trials," Arteriosclerosis, Thrombosis, and Vascular Biology, vol. 35, no. 3, pp. 689-699, 2015.

[212] A. Sahebkar and G. F. Watts, "New LDL-cholesterol lowering therapies: pharmacology, clinical trials, and relevance to acute 
coronary syndromes," Clinical Therapeutics, vol. 35, no. 8, pp. 1082-1098, 2013.

[213] M. Cuchel, E. A. Meagher, H. du Toit Theron et al., "Efficacy and safety of a microsomal triglyceride transfer protein inhibitor in patients with homozygous familial hypercholesterolaemia: a single-arm, open-label, phase 3 study," The Lancet, vol. 381, no. 9860 , pp. $40-46,2013$.

[214] C. P. Cannon, S. Shah, H. M. Dansky et al., "Safety of anacetrapib in patients with or at high risk for coronary heart disease," New England Journal of Medicine, vol. 363, no. 25, pp. 2406-2415, 2010.

[215] T. Teramoto, M. Shirakawa, M. Kikuchi et al., "Efficacy and safety of the cholesteryl ester transfer protein inhibitor anacetrapib in Japanese patients with dyslipidemia," Atherosclerosis, vol. 230, no. 1, pp. 52-60, 2013.

[216] A. Vogt, "Lipoprotein (a)-apheresis in the light of new drug developments," Atherosclerosis Supplements, vol. 1, no. 30, pp. 38-43, 2017.

[217] A. Kagawa, H. Azuma, M. Akaike, Y. Kanagawa, and T. Matsumoto, "Aspirin reduces apolipoprotein (a)(apo (a)) production in human hepatocytes by suppression of apo (a) gene transcription," Journal of Biological Chemistry, vol. 274, no. 48, pp. 34111-34115, 1999.

[218] M. Abifadel, M. Varret, J. P. Rabès et al., "Mutations in PCSK9 cause autosomal dominant hypercholesterolemia," Nature Genetics, vol. 34, no. 2, p. 154, 2003.

[219] J. C. Cohen, E. Boerwinkle, T. H. Mosley Jr, and H. H. Hobbs, "Sequence variations in PCSK9, low LDL, and protection against coronary heart disease," New England Journal of Medicine, vol. 354, no. 12, pp. 1264-1272, 2006.

[220] F. J. Raal, R. P. Giugliano, M. S. Sabatine et al., "Reduction in lipoprotein (a) with PCSK9 monoclonal antibody evolocumab (AMG 145): a pooled analysis of more than 1,300 patients in 4 phase II trials," Journal of the American College of Cardiology, vol. 63, no. 13, pp. 1278-1288, 2014.

[221] M. S. Sabatine, R. P. Giugliano, S. D. Wiviott et al., "Efficacy and safety of evolocumab in reducing lipids and cardiovascular events," New England Journal of Medicine, vol. 372, no. 16, pp. 1500-1509, 2015.

[222] D. Gaudet, D. J. Kereiakes, J. M. McKenney et al., "Effect of alirocumab, a monoclonal proprotein convertase subtilisin/ kexin 9 antibody, on lipoprotein (a) concentrations (a pooled analysis of $150 \mathrm{mg}$ every two weeks dosing from phase 2 trials)," The American Journal of Cardiology., vol. 114, no. 5, pp. 711-815, 2014. Sep 1.

[223] K. Fitzgerald, S. White, A. Borodovsky et al., "A highly durable RNAi therapeutic inhibitor of PCSK9," New England Journal of Medicine, vol. 376, no. 1, pp. 41-51, 2017.

[224] K. K. Ray, U. Landmesser, L. A. Leiter et al., "Inclisiran in patients at high cardiovascular risk with elevated LDL cholesterol," New England Journal of Medicine, vol. 376, no. 15, pp. 1430-1440, 2017.

[225] K. Arai, A. Orsoni, Z. Mallat et al., "Acute impact of apheresis on oxidized phospholipids in patients with familial hypercholesterolemia," Journal of Lipid Research, vol. 53, no. 8, pp. 1670-1678, 2012.

[226] S. N. Pokrovsky, A. V. Sussekov, O. I. Afanasieva, I. Y. Adamova, A. A. Lyakishev, and V. V. Kukharchuk, "Extracorporeal immunoadsorption for the specific removal of lipoprotein (a) (Lp (a) apheresis): preliminary clinical data," Chemistry and Physics of Lipids, vol. 1, no. 67, pp. 323-330, 1994.
[227] S. N. Pokrovsky, O. I. Afanasieva, M. S. Safarova et al., "Specific Lp (a) apheresis: a tool to prove lipoprotein (a) atherogenicity," Atherosclerosis Supplements, vol. 1, no. 30, pp. 166-173, 2017 Nov.

[228] S. T. Crooke and R. S. Geary, "Clinical pharmacological properties of mipomersen (Kynamro), a second generation antisense inhibitor of apolipoprotein B," British Journal of Clinical Pharmacology, vol. 76, no. 2, pp. 269-276, 2013.

[229] E. Merki, M. Graham, A. Taleb et al., "Antisense oligonucleotide lowers plasma levels of apolipoprotein (a) and lipoprotein (a) in transgenic mice," Journal of the American College of Cardiology, vol. 57, no. 15, pp. 1611-1621, 2011.

[230] J. Kurreck, "Antisense technologies: improvement through novel chemical modifications," European Journal of Biochemistry, vol. 270, no. 8, pp. 1628-1644, 2003.

[231] L. A. Carlson, A. Hamsten, and A. Asplund, "Pronounced lowering of serum levels of lipoprotein $\mathrm{Lp}$ (a) in hyperlipidaemic subjects treated with nicotinic acid," Journal of Internal Medicine, vol. 226, no. 4, pp. 271-276, 1989.

[232] A. M. Scanu and R. Bamba, "Niacin and lipoprotein (a): facts, uncertainties, and clinical considerations," The American Journal of Cardiology, vol. 101, no. 8, pp. s44-s47, 2008.

[233] S. J. Nicholls and P. J. Psaltis, "What role for lipoprotein (a) in clinical practice?” The Lancet Diabetes \& Endocrinology, vol. 5, no. 7, pp. 487-489, 2017.

[234] M. Li, R. Saeedi, S. W. Rabkin, and J. Frohlich, "Dramatic lowering of very high $\operatorname{Lp}(\mathrm{a})$ in response to niacin," Journal of Clinical Lipidology, vol. 8, no. 4, pp. 448-450, 2014.

[235] E. Stroes, D. Colquhoun, D. Sullivan et al., "Anti-PCSK9 antibody effectively lowers cholesterol in patients with statin intolerance: the GAUSS-2 randomized, placebo-controlled phase 3 clinical trial of evolocumab," Journal of the American College of Cardiology, vol. 63, no. 23, pp. 2541-2548, 2014.

[236] D. Bandyopadhyay, A. Hajra, K. Ashish, A. Qureshi, and S. Ball, "New hope for hyperlipidemia management: Inclisiran," Journal of Cardiology, vol. 71, no. 5, pp. 523-524, 2018.

[237] A. Vogt, "Hyperlipoproteinaemia (a)-apheresis and emerging therapies," Clinical Research in Cardiology Supplements, vol. 12, no. 1, pp. 12-27, 2017.

[238] S. N. Pokrovsky, O. I. Afanasieva, and M. V. Ezhov, "Lipoprotein (a) apheresis," Current Opinion in Lipidology, vol. 27, no. 4, pp. 351-358, 2016.

[239] B. R. Jaeger, Y. Richter, D. Nagel et al., "Longitudinal cohort study on the effectiveness of lipid apheresis treatment to reduce high lipoprotein (a) levels and prevent major adverse coronary events," Nature Reviews Cardiology, vol. 6, no. 3, pp. 229-239, 2009.

[240] U. Kassner, T. Schlabs, A. Rosada, and E. SteinhagenThiessen, "Lipoprotein (a)-an independent causal risk factor for cardiovascular disease and current therapeutic options," Atherosclerosis Supplements, vol. 1, no. 18, pp. 263-267, 2015.

[241] E. Roeseler, U. Julius, F. Heigl et al., "Lipoprotein apheresis for lipoprotein (a)-associated cardiovascular disease: prospective 5 years of follow-up and apolipoprotein (a) characterization," Arteriosclerosis, Thrombosis, and Vascular Biology, vol. 36, no. 9, pp. 2019-2027, 2016.

[242] P. M. Moriarty, "Lipoprotein apheresis: present and future uses," Current Opinion in Lipidology, vol. 26, no. 6, pp. 544$552,2015$. 